\title{
Immigration and Public Finances in OECD Countries
}

\author{
Hippolyte d'Albis* Ekrame Boubtane ${ }^{\dagger}$ Dramane Coulibaly ${ }^{\ddagger}$
}

This version: November 12, 2018

\begin{abstract}
This paper shows that the macroeconomic and fiscal consequences of international migration are positive for OECD countries, and suggests that international migration produces a demographic dividend by increasing the share of the workforce within the population. The estimation of a structural vector autoregressive model on a panel of 19 OECD countries over the period 1980-2015 reveals that a migration shock increases GDP per capita through a positive effect on both the ratio of working-age to total population and the employment rate. International migration also improves the fiscal balance by reducing the per capita transfers paid by the government and old-age public spending per capita. To rationalize these findings, an original theoretical framework is developed. This framework highlights the roles of both the demographic structure and intergenerational public transfers and shows that migration is beneficial to host economies characterized by aging populations and large public sectors.
\end{abstract}

JEL classification: E20, F22, J61.

Keywords: Immigration, public finances, overlapping-generation model, panel VAR

*Paris School of Economics, CNRS. Corresponding author, E-mail: hdalbis@psemail.eu.

${ }^{\dagger}$ University Clermont Auvergne, CNRS, IRD, CERDI, F-63000 Clermont-Ferrand, France.

${ }^{\ddagger}$ EconomiX-CNRS, University Paris Nanterre. 


\section{Introduction}

According to United Nations (2017), OECD countries host more than $40 \%$ of all immigrants worldwide. Moreover, the share of immigrants in the population of those countries has increased from $7 \%$ in 1990 to $13 \%$ in 2017. Because global population trends include a predicted concentration of young people in Africa, immigration figures are likely to rise ${ }^{1}$. This article analyzes the effects of international migration on the macro-economic and fiscal situation of host countries. This point is important because most OECD countries structurally run public deficits. Moreover, opinion polls show that whatever the position of natives toward immigrants, the cost for public finances appears the main economic concern associated with international migration. For instance, according to European Social Survey (2014), 52\% of European natives say they agree to allow many or some immigrants from poorer countries outside Europe to come and live in their home country. Among them, 30\% believe that, on balance, immigrants take more (in terms of health and welfare services used) than they add (in terms of taxes payed), whereas $18 \%$ believe that immigrants generally take jobs away from native workers. Among those who say they want few or no immigrants, these proportions are $61 \%$ and $45 \%$, respectively.

An analysis of the fiscal effects of immigration faces two main challenges. The first is reverse causality, because public spending, for example, can not only rise with flows of migrants but also increase those flows. The second is the focus on macroeconomic and fiscal variables, whose data coverage is considerably lower than that on microeconomics ones. To date, the literature on the effect of migration on public finance is quite inconclusive with respect to the sign of the effects, which are in all cases expected to be quantitatively low (Rowthorn, 2008; Liebig and Mo, 2013).

In this paper, we propose empirical evidence and an original theoretical framework that suggest that the macroeconomic and fiscal consequences of international migration are positive for OECD countries. Most notably, we explore the role of changes in the age structure of the population induced by net flows of migrants. As noted by Bloom

\footnotetext{
${ }^{1}$ For instance, the World Bank forecasts that Sub-Saharan Africa alone will by 2050 contain nearly one-third of the world's 15-24-year-olds. This population boom far exceeds the absorption capacity of local labor markets (Margolis and Yassine, 2015).
} 
et al. (2003) and Lee and Masson (2007), an increase in the share of the working-age population can produce a demographic dividend with respect economic growth and effect virtuous cycles of wealth creation. Because many migrants are of working age ${ }^{2}$, we have focused our analysis on the demographic aspect of migration and are able to present robust evidence of the existence of a demographic dividend of international migration in OECD countries.

We estimate a structural vector autoregression (VAR) on a panel of 19 OECD countries with annual data for 1980-2015. Since the initial article by Blanchard and Perotti (2002), the VAR approach has been widely used for fiscal studies (Alesina et al., 2002; Beetsma et al., 2006, 2008; Monacelli et al., 2010; Beetsma and Guiliodori, 2011; Brückner and Pappa, 2012). This method's multivariate dynamic structure appears to us to be appropriate for assessing the fiscal effects of international migration. Most notably, it proposes an identification strategy for assessing the dynamic effect of an exogenous migration shock on the economic and public finances of the host country. This strategy is suitable for macroeconomic studies, which complement micro-economic one that addresses the endogeneity issue with instrumental variables ${ }^{3}$.

We find that international migration is beneficial to OECD countries. In response to an exogenous shock that increases the net flow of migrants by one incoming individual per thousand inhabitants, GDP per capita rises significantly by 0.25 percent the year of the shock and peaks at 0.31 percent after one year; additionally, fiscal balance improves by 0.12 percentage points of GDP at its peak, which occurs the year of the shock and one year after the shock. The estimates confirm those found in many studies using different methodologies and data (Clemens, 2011; Ager and Brückner, 2013; Ortega and Peri, 2014).

To highlight the crucial importance of the demographic dividend of international migration, we initially use an accounting decomposition of the GDP per capita and show that following a migration shock, both the ratio of working-age to total population and

\footnotetext{
${ }^{2}$ In $2017,80 \%$ of immigrants in OECD countries were aged 15 to 64 whereas the share of this age group within total resident population amounted to $64 \%$ (United Nations, 2017).

${ }^{3}$ For a discussion on the difficulties arising with the choice of a relevant instrument see Clemens and Hunt (2017).
} 
the employment rate increase. Then, we propose a decomposition of public spending and analyze the effect of a migration shock on some of its components. Specifically, we show that net flow of migrants reduces old-age spending but increases family spending, which suggests that the demographic dividend of international migration goes through public finances. Moreover, spending on active labor market programs increase following a migration shock while spending associated with unemployment benefits decrease. This point can be explained by the fact that international migration significantly reduces the unemployment rate in the host countries.

To understand the main mechanisms involved, we ultimately developed an analytical framework. This framework relies on an original overlapping-generation model in which migrants arrive as working age adults. To highlight in our model the demographic aspect of migration, we make no further assumptions that might lead to positive effects of international migration, such as complementarity between migrants and native-born, even when these effects are identified in the literature (Blau and Mackie, 2016). We lay out the simple conditions under which the net flow of migrants is positive for per capita income, savings and net taxes. In particular, we show that the effect is positive if the population growth rate is low and the share of public expenditure dedicated to young and old populations is high. Because OECD economies typically have aging populations and often have large intergenerational transfers, we deduce that the model helps in understanding the positive effect of international migration found in our empirical analysis. These results reinforce previous studies' findings that highlighted the role of the age structure of the population on macroeconomic performances (Boucekkine et al., 2002; Beaudry and Collard, 2003; d'Albis, 2007; Lee et al., 2014). Our model also provide a theoretical framework for the analysis of the demographic dividend of international migration.

The article is structured as follows. Section 2 presents the related literature. Section 3 describes the data and the econometric methodology. Section 4 presents the empirical results. Section 5 introduces an original overlapping-generation model that explains the mechanisms underlying our main results. Section 6 concludes. 


\section{Relationship to the Literature}

The effect of international migration on public finances has been examined in articles that can be classified by methodology (Rowthorn, 2008; Liebig and Mo, 2013). They use either cost-benefit analysis, general equilibrium models or VAR models.

The main group is based on accounting techniques following the pioneer work of Blau (1984). Static studies (as, e.g., Dustmann and Frattini, 2014) have calculated the costs and benefits of immigrants for public finances for a given year. However, it is an oversimplification to restrict analysis to a single year, because immigrants are likely to live for a period in the host country and might raise a family there. Auerbach and Oreopoulos (1999) note that a dynamic approach is needed to calculate the net contribution to public finances of immigrants and their descendants over their duration of residence in the host country. Preston (2014) notes that immigrants' contributions change over time as they stay longer and gradually acquire the specific skills needed to join the labor market in that country. National Research Council (1997) includes a pioneering study by Lee and Miller (1997) that forecasts immigrants' net contributions over time. This approach has since been developed using generational accounting tools to determine the net present value of immigrants' contributions (Auerbach and Oreopoulos, 1999; Lee and Miller, 2000). Its results show that the net contribution is relatively low, which can be explained by the demographic weight of the population concerned. If immigrants represent only $10 \%$ of the total population, their effect on public finances can only be low. More importantly, externalities, complementarities and, more broadly, any general equilibrium effect are not included in those accounting approaches.

A second group of studies consequently seeks to complement these results with applied general equilibrium models (Storesletten, 2000, 2003). This research does include the interactions between variables, but the results are heavily dependent upon nonobservable and difficult-to-calibrate parameters such as the degree of complementarity between native-born and immigrants in the production process. These general equilibrium models are occasionally used to make forecasts, but they crucially hinge on assumptions made concerning the future development of incomes and population (Blau 
and Mackie, 2016).

Within the literature using time-series for the analysis of the relationship between international migration and host country' economic conditions (as, e.g., Pope and Withers, 1993; Gross, 2002; Damette and Fromentin, 2013), a third group of studies has recently proposed to estimate a structural VAR model to assess the fiscal effect of a migration shock (d'Albis et al., 2018; Furlanetto and Robstad, 2016). In d'Albis et al. (2018), we estimated a VAR model for a panel of 15 European countries for 1985-2015 to analyze the effects of flows of asylum seekers and permanent migrants on economic and fiscal performance. Furlanetto and Robstad (2016) use Norwegian data over the period 1990Q1-2014Q2 to evaluate the effect of shocks of immigrants from OECD countries on fiscal and macroeconomic variables.

With respect to these recent studies, the contribution of the present paper is to identify demographic dividend of international migration. It examines the economic and fiscal effects that arise from the increase in the workforce due to net flows of migrants. It relies on the estimation of VAR models and uses a tractable general equilibrium model to explain the main mechanisms.

\section{Data and Empirical Strategy}

\subsection{Data}

Our sample includes yearly observations from 1980 to 2015 for 19 OECD countries that are selected to have a set of long-span data. We consider all of the OECD member countries who signed the Convention on the OECD before 1980 for which the fiscal data are available over the whole sample period in Economic Outlook databases ${ }^{4}$. Our sample includes 4 OECD non-European countries: Australia, Canada, Japan and the United States, and the 15 Western European countries: Austria, Belgium, Denmark, Finland, France, Germany, Ireland, Iceland, Italy, the Netherlands, Norway, Spain, Sweden, Portugal and the United Kingdom. These OECD countries, omitting Japan, are also the

\footnotetext{
${ }^{4}$ Fiscal data are not available in the Economic Outlook database over the the whole period 1980-2015 for Turkey or Greece or Luxembourg or Switzerland or New-Zealand.
} 
main destinations countries for international migrants ${ }^{5}$.

\section{Fiscal and Economic Variables}

Fiscal variables are obtained from the OECD Economic Outlook databases (OECD, 2016). We consider three main variables: government purchases, transfers paid and tax revenues received by the general government. Consistent with the literature on fiscal multipliers (Beetsma et al., 2006, 2008; Beetsma and Guiliodori, 2011), we compute the first fiscal variable, government purchases, as the sum of general government final consumption expenditure and general government fixed capital formation. The second variable, transfers paid by the general government, is computed as the sum of social security benefits and other current payments. The third variable, tax revenues collected by the general government, includes direct and indirect taxes on production and imports, social security contributions and other receipts. All variables are expressed in real terms using the appropriate deflator (see Appendix A-1 for more details).

Of these three variables, we define (i) net taxes as the difference between tax revenues received and transfers paid by the general government; (ii) public spending as the sum of the government purchases and transfers, and (iii) fiscal balance as the difference between general government tax revenues and spending.

We also consider social public spending from the OECD Social Expenditure database (SOCX), which provides comparable data on public and private social expenditures for the 19 countries of our sample (OECD, 2018a; Adema et al., 2011). In the SOCX database, expenditures for social purposes are grouped in nine social-policy areas. In our estimates, we consider the four of these areas that are the most relevant for our analysis: old age, family, active labor market programs, and unemployment spending (see Appendix A-1 for more details).

Economic data that are used in this study are the GDP, total employment and the unemployment rate, which are taken from the OECD Economic Outlook databases.

\footnotetext{
${ }^{5}$ According to United Nations (2017), in 2015, 45\% of all international migrants lived in one of the 19 OECD countries we consider in our sample.
} 


\section{Demographic Variables}

Demographic variables are from the Demography and migration (demo) database of Eurostat for the European countries and from OECD (2017) for the OECD non-European countries. We use the annual average population to express the economic and fiscal variables in per capita terms. We also consider the working-age average population to compute (i) the ratio of working-age to total population; (ii) the GDP to working-age population, and (iii) the employment rate as the total employment to working-age population (following the OECD and Eurostat definitions of employment rate). Net flow of migrants is evaluated using net migration data, expressed as a rate per 1000 population. The net migration is calculated by Eurostat and OECD (2017) as the difference between the total change and the natural change of the "usual resident" population. Net migration then accounts for the difference between the number of immigrants and the number of emigrants. It makes no distinction between nationals and foreigners ${ }^{6}$.

To the best of our knowledge, net migration data are the only annual data available for the period 1980-2015 for the 19 OECD countries we consider. Most available data are related to stocks of immigrants and are usually obtained from population censuses. Moreover, they are usually available for limited periods, mostly at 10-year intervals. Some data (see for instance Brücker et al., 2013) are available at 5-year intervals but they are built by interpolating variables observed at 10-year intervals. Furthermore, net migration data, which are based on population and vital statistics, are much more comparable than are data on inflows or outflows of foreigners published by Eurostat, OECD (2015) or United Nations (2015). Comparability across countries is indeed difficult because national systems of registering permanent entries and exits are heterogeneous. Each country uses its available sources (e.g, population registers, international passenger survey or residence permits) to compute entries ${ }^{7}$, and a few countries collect information on exits.

\footnotetext{
${ }^{6}$ The decomposition by country of birth of net migration from Eurostat became available only begining in 2008. The temporal dimension is thus insufficient to run a VAR model with those data.

${ }^{7}$ See Lemaître et al. (2006) for more details on the limitation of available national statistics on foreigners in OECD countries and for a discussion on the sources and methods of harmonized statistics on inflows. Moreover, for the first time, the 2006 edition of the International Migration Outlook included harmonized statistics on inflows of foreign nationals for 16 countries of our sample for 2003 and 2004. The harmonized data on the inflows in 18 OECD countries of our sample have only been available since
} 
Our data allow for an analysis of the fiscal effect of international migration over time. This analysis complements the branch of the literature that uses data on the stock of immigrants and detailed fiscal information that distinguish fiscal contributions and the benefits of immigrants and natives. Due to comparability issues, most of these studies are country-specific except for Liebig and Mo (2013), which is based on 27 OECD countries using data collected around 2008.

\subsubsection{Descriptive Statistics}

Table 1 provides the mean values of our main variables over the period 1980-2015 ${ }^{8}$ GDP per capita in constant 2010 USD ranges from $\$ 18,534$ for Portugal to $\$ 73,420$ for Norway. The sample averages of government purchases and transfers per capita in constant 2010 USD range respectively from $\$ 4,071$ and $\$ 4,314$ in Portugal to $\$ 17,882$ and $\$ 17,815$ in Norway. Tax revenues per capita in constant 2010 USD ranges on average from $\$ 6,926$ for Portugal to $\$ 40,080$ for Norway. Over the period 1980-2015, the United Stated recorded the largest deficit on average followed by Italy and Portugal (-8.20, -7.92 and -7.80 in percentage points of GDP, respectively). The lowest deficits on average were recorded in Iceland and in Finland (-0.85 and -1.68 in percentage points of GDP, respectively), whereas Norway recorded a surplus on average (5.34 in percentage points of GDP). Japan has the lowest net flow of migrants on average (-0.08 per 1,000 population), followed by Portugal and Iceland (0.05 and 1.00 per 1,000 population, respectively), whereas the highest net flows of migrants on average are recorded in Australia, Canada and Spain (6.55, 5.22 and 3.90 per 1,000 population, respectively).

Figure 1 displays the evolution of the net migration rate over time for each country under consideration. It shows that this rate has significantly varied over time in almost all countries.

2007, a temporal dimension that is insufficient to estimate a VAR model.

${ }^{8}$ See also Table A-1 in the Appendix for the mean values of the other variables. 
Table 1: Summary statistics, averages per country over the sample period (1980-2015)

\begin{tabular}{|c|c|c|c|c|c|c|}
\hline Country & $\begin{array}{l}\text { Net flow } \\
\text { of migrants } \\
\text { (per } 1,000)\end{array}$ & $\begin{array}{c}\text { GDP } \\
\text { per capita } \\
(\mathrm{PPP}, 2010 \mathrm{USD})\end{array}$ & $\begin{array}{c}\text { Gov Purchases } \\
\text { per capita } \\
\text { (PPP, } 2010 \text { USD })\end{array}$ & $\begin{array}{c}\text { Transfers } \\
\text { per capita } \\
(\mathrm{PPP}, 2010 \mathrm{USD})\end{array}$ & $\begin{array}{c}\text { Tax revenues } \\
\text { per capita } \\
(\mathrm{PPP}, 2010 \mathrm{USD})\end{array}$ & $\begin{array}{c}\text { Fiscal Balance } \\
\text { to GDP ratio } \\
\text { (in } \%)\end{array}$ \\
\hline Austria & 3.53 & 38771 & 8815 & 11780 & 19058 & -4.04 \\
\hline Belgium & 2.41 & 37106 & 9195 & 10938 & 17894 & -6.68 \\
\hline Denmark & 2.20 & 50736 & 14296 & 14755 & 27245 & -3.89 \\
\hline Finland & 1.51 & 37245 & 9553 & 10548 & 19428 & -1.69 \\
\hline France & 1.16 & 35549 & 9505 & 10078 & 17505 & -5.76 \\
\hline Germany & 3.82 & 35951 & 7692 & 9187 & 15757 & -3.17 \\
\hline Iceland & 1.26 & 35212 & 9117 & 5560 & 14296 & -0.86 \\
\hline Ireland & 1.00 & 35902 & 7170 & 7060 & 12610 & -5.00 \\
\hline Italy & 2.14 & 32428 & 7139 & 9122 & 13824 & -7.93 \\
\hline Netherlands & 1.64 & 41322 & 11186 & 9647 & 18622 & -5.45 \\
\hline Norway & 3.67 & 73420 & 17882 & 17815 & 40080 & 5.34 \\
\hline Portugal & 0.50 & 18535 & 4071 & 4314 & 6926 & -7.80 \\
\hline Spain & 3.90 & 25283 & 5443 & 5104 & 9280 & -4.99 \\
\hline Sweden & 3.41 & 42471 & 12896 & 12149 & 23159 & -4.82 \\
\hline United Kingdom & 1.97 & 32722 & 6883 & 6614 & 12048 & -4.28 \\
\hline 15 European Countries & 2.28 & 38177 & 9390 & 9645 & 17849 & -4.07 \\
\hline Australia & 6.55 & 47251 & 9990 & 7552 & 16125 & -3.24 \\
\hline Canada & 5.52 & 40955 & 10108 & 8653 & 16531 & -5.82 \\
\hline Japan & -0.08 & 39303 & 8363 & 6215 & 12265 & -5.53 \\
\hline United States & 3.67 & 41073 & 8047 & 8551 & 13228 & -8.20 \\
\hline 19 OCDE countires & 2.62 & 39013 & 9335 & 9245 & 17152 & -4.42 \\
\hline
\end{tabular}

Source: Authors' computations based on data from Eurostat and, OECD (2016), OECD (2017) and OECD (2018b) databases. 
Figure 1: Net flows of migrants in 19 OECD countries, 1980-2015, annual data
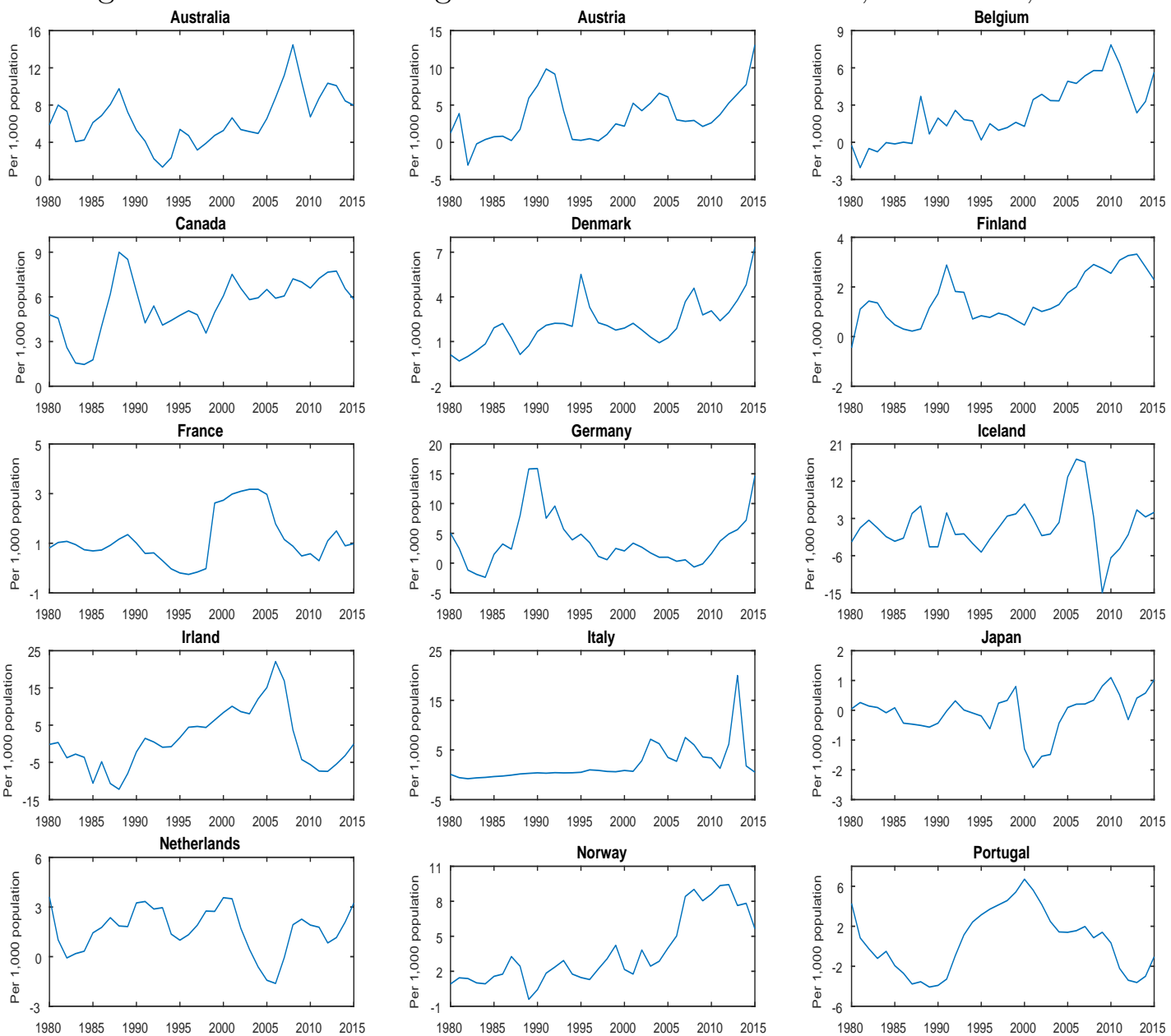

Norway

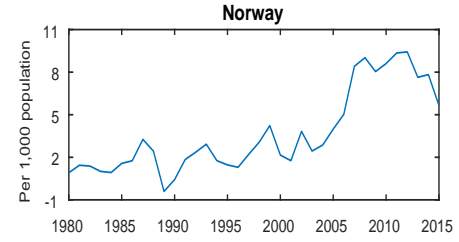

Portugal

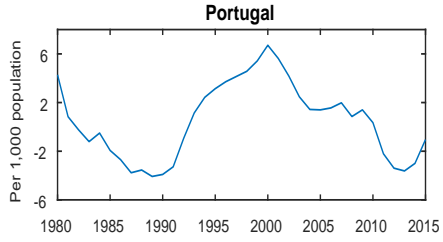

Spain

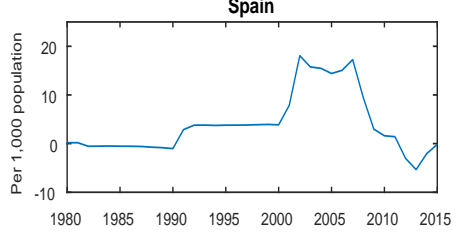

Sweden

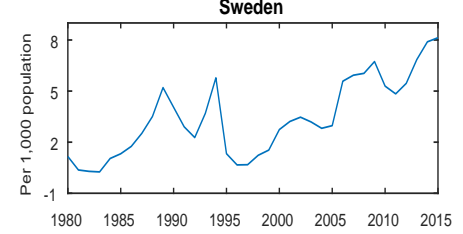

United Kingdom
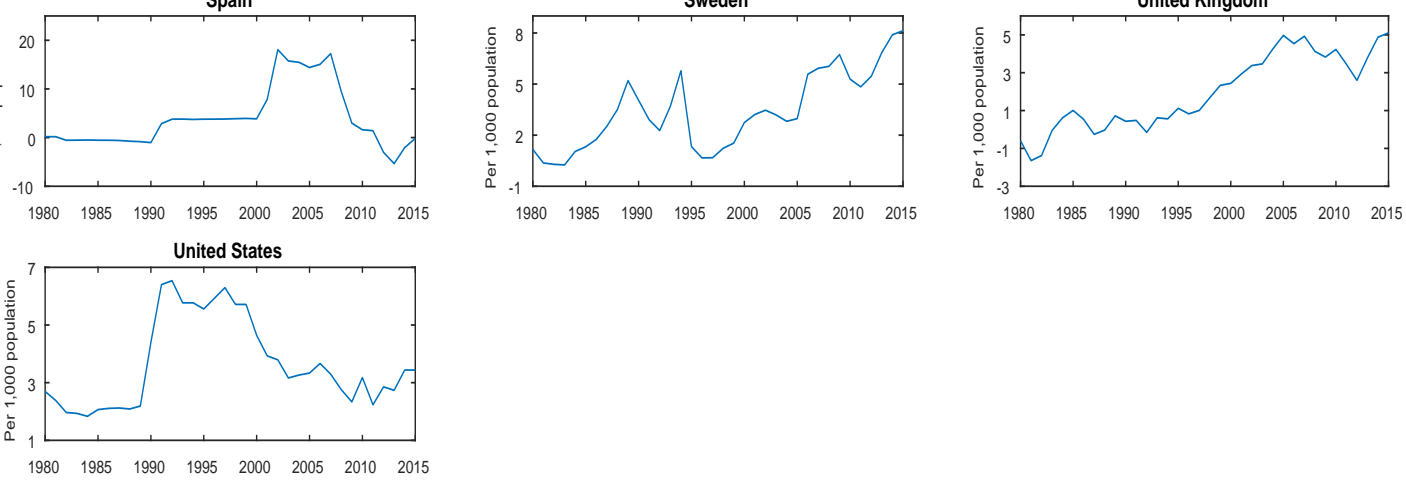

Source: Authors' computations based on data from Eurostat and OECD (2017) databases.

\subsection{Empirical Strategy}

We define a structural VAR model to draw inference on the economic and fiscal effects of international migration, following a methodology developed in the empirical fiscal policy literature that started with the seminal paper of Blanchard and Perotti (2002). Given 
the available time-series data on international migration, we consider a panel VAR that allows us to obtain an adequate sample size using OECD annual data, as in Alesina et al. (2002).

\subsubsection{Empirical Model}

Our empirical model is specified as follows:

$$
\begin{aligned}
Z_{i t} & =A(L) Z_{i t}+v_{i}+\lambda_{i} t+f_{t}+\varepsilon_{i t} \\
& =\sum_{s=1}^{p} A_{s} Z_{i t-s}+v_{i}+\lambda_{i} t+f_{t}+\varepsilon_{i t} \quad \text { for } \quad i=1, \ldots, N \text { and } t=1, \ldots, T
\end{aligned}
$$

where $Z_{i t}=\left(z_{i t}^{1}, \ldots, z_{i t}^{K}\right)^{\prime}$ is a vector of $K$ endogenous variables, $A(L)$ is a matrix polynomial in the lag operator $L$ with coefficients given by the fixed $(K \times K)$ matrices, $A_{s}$, $v_{i}=\left(v_{i}^{1}, \ldots, v_{i}^{K}\right)^{\prime}$ is the vector of country fixed-effects, $\lambda_{i} t$ represents country-specific time trends, $f_{t}$ is the common time-specific effect, and $\varepsilon_{i t}=\left(\varepsilon_{i t}^{1}, \ldots, \varepsilon_{i t}^{K}\right)^{\prime}$ is the $(K \times 1)$ vector of residuals satisfying $E\left(\varepsilon_{i t}\right)=0$ and $E\left(\varepsilon_{i t} \varepsilon_{i \tau}^{\prime}\right)=\Omega . \mathbb{1}\{t=\tau\} \forall i$ and $t$.

Thus, the potential heterogeneity in our panel data setting is mitigated both by considering OECD economies that are somewhat similar, and by including country-fixed effects $\left(v_{i}\right)$ and country-specific time trends $\left(\lambda_{i} t\right)$. Moreover, we account for cross-country contemporaneous interdependence by introducing year-specific effects $\left(f_{t}\right)$, as in Beetsma et al. $(2006,2008)$ and Beetsma and Guiliodori $(2011)^{9}$.

Our panel VAR will be estimated with $N=19$ and $T=36$. To address the short- $T$ dynamic panel data bias (also known as the Nickell bias, Nickell, 1981), we estimate our panel VAR using the bias-corrected fixed-effects technique developed by Hahn and Kuersteiner (2002). This technique is appropriate when the sizes of the time dimension $T$ and the cross-sectional dimension $N$ are of the same order of magnitude, i.e. when $0<\lim N=T<\infty$ (as here). As argued in Hahn and Kuersteiner (2002), because the approach does not require a preliminary consistent estimator, it can therefore be

\footnotetext{
${ }^{9}$ We are aware that using common time effects might absorb the cross-country co-movement in structural shocks (Beetsma et al., 2006). The estimations without the common time effect are available upon request to the authors; findings are unchanged.
} 
perceived as an implementable version of Kiviet's (1995) bias-corrected fixed-effects estimator of the single equation. More importantly, it is suitable for VAR(p) models with higher order $p>1$ using the fact that any higher order VAR(p) process can be rewritten in $\operatorname{VAR}(1)$ form, by imposing blockwise zero and identity restrictions (Hahn and Kuersteiner, 2002; Lütkepohl, 2005, p. 15). ${ }^{10}$ Moreover, the Monte Carlo experiment conducted by Hahn and Kuersteiner (2002) showed that the efficiency of the bias-corrected estimator measured by the root mean squared error (RMSE) often dominates that of the GMM estimator.

Using the AIC (Akaike information criterion) and BIC (Bayesian information criterion), we set the lag length of the system to two so as to eliminate any autocorrelation in the residuals. The results are insensitive to any lag length greater than two.

\subsubsection{Baseline Specification}

Following the studies on fiscal multipliers that use annual data (Beetsma et al., 2006, 2008; Beetsma and Guiliodori, 2011), we identify structural shocks via Choleski decomposition. For our baseline model, we consider the following system $Z_{i t}^{1}=\left[m_{i t}, g_{i t}, n t_{i t}, y_{i t}\right]^{\prime}$, where $m_{i t}$ is the logarithm of the ratio of net migration to population ${ }^{11}, g_{i t}$ is the logarithm of per capita government purchases, $n t_{i t}$ is the logarithm of per capita net taxes and $y_{i t}$ is the logarithm of per capita GDP (see Appendix A-1 for more details).

Panel unit root tests fail to accept the null hypothesis of the unit root on detrending the variables (with a country-specific linear trend). We then consider a VAR model on variables in levels, controlling for country heterogeneity (by including country-specific effects and country-specific time trends) and cross-country interdependence (by including year-specific effects). The corresponding structural VAR (SVAR) is given by the following specification:

\footnotetext{
${ }^{10}$ For an example of an application in panel VAR estimations, see Juessen and Linnemann (2012).

11 To work with negative values on net migration, we use $\log (1+$ net migration as a share of population).
} 


$$
B_{0}\left(\begin{array}{c}
m_{i t} \\
g_{i t} \\
n t_{i t} \\
y_{i t}
\end{array}\right)=B(L)\left(\begin{array}{c}
m_{i t} \\
g_{i t} \\
n t_{i t} \\
y_{i t}
\end{array}\right)+B_{0} \cdot v_{i}+B_{0} \cdot \lambda_{i} t+B_{0} \cdot f_{t}+\left(\begin{array}{c}
e_{i t}^{m} \\
e_{i t}^{g} \\
e_{i t}^{n t} \\
e_{i t}^{y}
\end{array}\right)
$$

where $B_{0}$ is a $(K \times K)$ matrix such that $e_{i t}=\left(e_{i t}^{m}, e_{i t}^{g}, e_{i t}^{n t}, e_{i t}^{y}\right)^{\prime}=B_{0} \varepsilon_{i t}$ or $\varepsilon_{i t}=B^{-1} e_{i t}$, where $e_{i t}$ represents the vector of structural shocks that are mutually uncorrelated, i.e. $E\left(e_{i t} e_{i t}^{\prime}\right)=B_{0} \Omega B_{0}^{\prime}=I_{K}$, and $B(L)$ is a matrix polynomial in the lag operator $L$.

In our Choleski decomposition, structural shocks are identified by choosing $B_{0}^{-1}$ as the unique lower-triangular Choleski factor of $\Omega$, i.e., $\Omega=B_{0}^{-1}\left(B_{0}^{-1}\right)^{\prime}$ and,

$$
B_{0}=\left(\begin{array}{cccc}
\beta^{m m} & 0 & 0 & 0 \\
\beta^{g m} & \beta^{g g} & 0 & 0 \\
\beta^{n t m} & \beta^{n t g} & \beta^{n t n t} & 0 \\
\beta^{y m} & \beta^{y g} & \beta^{y n t} & \beta^{y y}
\end{array}\right)
$$

This identifying scheme relies on the assumption that variables ordered first in the VAR can affect the other variables contemporaneously, whereas variables ordered later can affect those ordered first only with lags. The scheme assumes, therefore, that international migration can contemporaneously affect the economic and fiscal performances of the host country and might respond to them only with a lag. This assumption is supported by an international migration process in which the decision to migrate is generally made based on the host country's economic conditions over previous years (Boubtane et al., 2013; d'Albis et al., 2016, 2017, 2018). As noted in Smith and Thoenissen (2018), this identifying assumption appears reasonable given that international migration can be a lengthy process. Following the standard practice in the literature on the effect of fiscal policy, we assume that government purchases can contemporaneously affect net taxes and GDP, whereas changes in net taxes and GDP can at best affect government purchases with a lag. Net taxes are allowed to contemporaneous affect GDP and might at best be influenced by GDP only with a lag. This identifying assumption is justified by institutional knowledge on fiscal policy as follows: (i) decisions on changing government purchases are 
generally made in the Budget Act that is presented before the new fiscal year, whereas adjustments during the current year can be considered negligible (Beetsma et al., 2006, 2008; Beetsma and Guiliodori, 2011) and; (ii) net taxes include both cyclically-sensitive components (some spending items such as social benefits and other current receipts) and discretionary components under the government's control that are also determined in the Budget Act before the new fiscal year.

The response of the fiscal balance, defined as $\left(N T_{t}-G_{t}\right) / Y_{t}$, is computed as follows:

$$
\frac{N T_{t}}{Y_{t}}\left[\hat{N T}-\hat{Y}_{t}\right]-\frac{G_{t}}{Y_{t}}\left[\hat{G}_{t}-\hat{Y}_{t}\right]
$$

where $Y, G$ and $N T$ are per capita, GDP, government purchases and net taxes, respectively, and where $\hat{Y}, \hat{G}$ and $\hat{N T}$ are the impulse responses of the corresponding variables. The ratios $G / Y$ and $N T / Y$ are approximated by the overall sample mean.

We are aware that transfers include items that are cyclically-sensitive. The estimation of the baseline model using cyclically adjusted net taxes instead of unadjusted net taxes is available by request to the authors. The use of cyclically adjusted net taxes yields roughly the same impulse responses ${ }^{12}$.

As shown in Appendix A-2, our model is able to replicate the results from recent studies on the macro-economic effects of fiscal stimuli (Beetsma et al., 2006, 2008 and Beetsma and Guiliodori, 2011).

\section{Empirical Results}

We analyze the macroeconomic and fiscal effects of international migration. We initially present some benchmark impulse response functions and then extend the analysis by decomposing the public spending and adding new variables in the model.

\footnotetext{
${ }^{12}$ See Beetsma and Guiliodori (2011) and d'Albis et al. (2018) for more discussions of this issue.
} 


\subsection{Immigration, Output and Public Finances}

We initially present our basic estimates of the dynamic consequences of a migration shock on economic and fiscal outcomes of OECD host countries. The size of the migration shock is set to one incoming individual per thousand inhabitantss. The responses are shown in Figure 2, and coefficients are reported in Appendix Table B-1.

Figure 2: Responses to migration shock in the baseline model
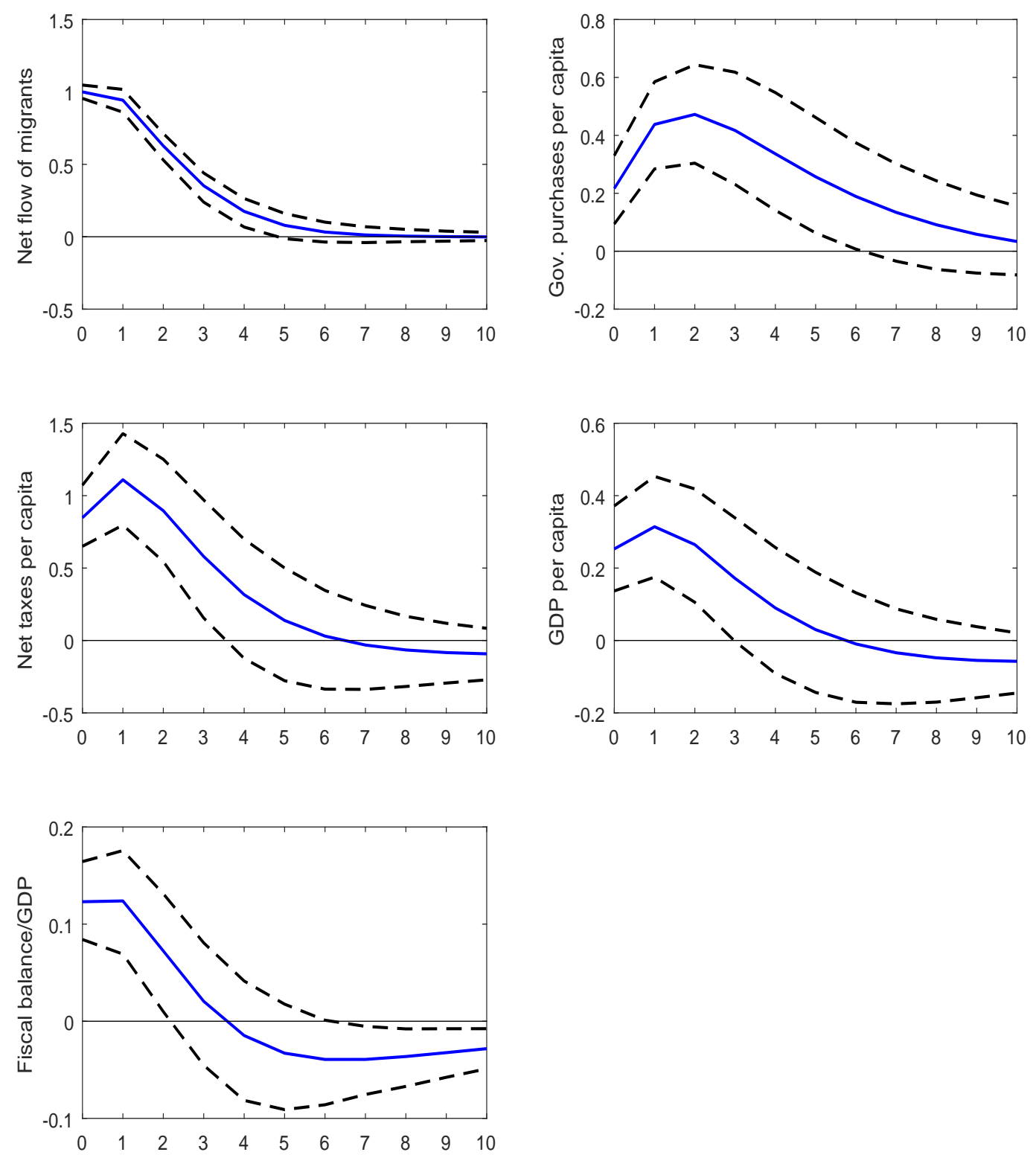

Notes: The solid line gives the estimated impulse responses. Dashed lines give the $90 \%$ confidence intervals generated by Monte Carlo with 5000 repetitions. The responses of net flow of migrants are in per 1000 points change. For per capita variables, the responses are in percentage change. For the fiscal balance to GDP ratio, the responses are in percentage points change. 
The results presented in Figure 2 and in Appendix Table B-1 show the responses to an increase in the net flow of migrants. From Figure 2, we first notice that international migration monotonically responds to its own shock; the increase remains significant for approximately four years. Then, following the migration shock, we observe that GDP per capita increases significantly by 0.25 percent the year of that shock and by 0.31 percent at the peak (one year after the shock). This finding is consistent with previous empirical studies such as Boubtane et al. (2013) and Ortega and Peri (2014). Moreover, the migration shock leads to a significant increase in both government purchases and net taxes. Government purchases per capita rise by 0.22 percent the year of the migration shock and by 0.47 percent at the peak (two years after the shock) while the effect on net taxes per capita is 0.85 percent the year of the migration shock and 1.11 percent at the peak (one year after the shock). Consequently, in response to the migration shock, the fiscal balance improves significantly by around 0.12 percentage points of GDP the year of that shock (the peak). The improvement remains significant after two years. The responses are similar to those found by d'Albis et al. (2018) for 15 European countries over the period 1985-2015.

Figure 3: The contribution of migration shocks to explain fluctuations
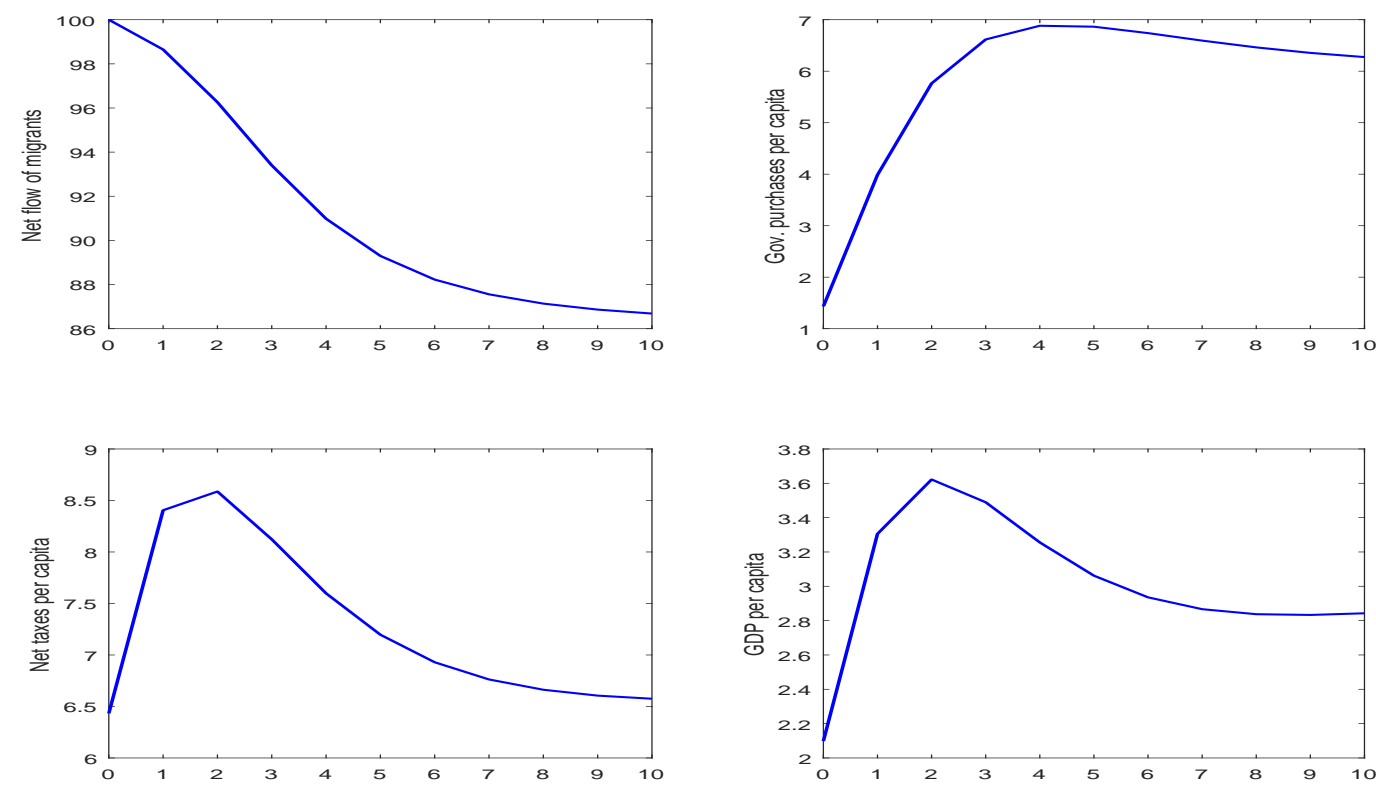

Notes: The percentage of fluctuations attributable to migration shocks is the forecast error variance of the corresponding variable explained by migration shock. 
The forecast error variance decomposition analysis reported in Figure 3 and in Appendix Table B-2 shows that, at the year of the shock, the contributions of migration shocks in explaining the volatility of per capita; government purchases, net taxes and GDP are 1.43, 6.43 and 2.10 percent, respectively. Over ten years, these contributions are $6.27,6.58$ and 2.84 percent, respectively. Migration shocks are thus relatively more important in explaining fluctuations of per capita fiscal variables than in explaining fluctuations of GDP per capita. These results stress the importance of economic and fiscal shocks in explaining the fluctuations of their respective variables. The contribution of migration shocks in explaining the fluctuations of GDP per capita in our panel VAR for 19 OECD countries is quite comparable to the results obtained by Smith and Thoenissen (2018). Using an estimated dynamic stochastic general equilibrium (DSGE) model, they find that the contribution of the migration shock to the variance of per capita GDP in New Zealand is between 0.2 and 19 percent. The authors find that migration shocks account for a large part of the variability of per capita GDP if migrants have a higher level of human capital than do locals. Smith and Thoenissen (2018) results are consistent with those of Furlanetto and Robstad (2016), who focus on the effect of immigrants from OECD countries in Norway. Estimating a VAR model on Norwegian data, Furlanetto and Robstad (2016) find that migration shocks explain on average approximately 15-20 percent of GDP fluctuations.

Our results are not altered after the investigation of the potential presence of heterogeneity in our panel. Specifically, to check whether our results could be biased by sample heterogeneity, we evaluated the responses for alternative samples by excluding successively all non-European countries, the 4 countries with the lowest net flows of migrants, the 4 countries with the highest net flows of migrants, the 4 countries with the lowest fiscal balance to GDP ratio, the 4 countries with the highest fiscal balance to GDP ratio, the 4 countries with the highest share of skilled migrants ${ }^{13}$ and the 4 countries with the lowest share of skilled migrants. The response functions, presented in Table B-3, reveal

\footnotetext{
${ }^{13}$ To select the countries with the more- (less-) skilled international migrants, we use Boubtane et al. (2013)'s estimates of the share of tertiary educated among recent migrants averaged over the period 1986-2006 in Table 4 p. 355.
} 
that our benchmark results are robust. The variance decomposition reported in Table B-4 shows that, even accounting for heterogeneity, the contribution of migration shocks in explaining fluctuations of GDP remains relatively low. However, the contribution of migration shocks in the variance of economic and fiscal variables is higher for the sample when the 4 countries with the lowest share of skilled migrants are excluded.

In addition, our results are robust to the issues related to anticipations and to the use of an alternative identification strategy based on sign restrictions. Indeed, our results are obtained using a recursive identification scheme based on the assumption that international migration is the most exogenous variable in the sense that the net flow of migrants can contemporaneously affect the economic and fiscal variables in the host country but might respond to them only with a lag. In recursive identification schema, results depend on the order of the variables. Thus, the assumption of ordering migration variable first is key and is justified by the fact that the decision to migrate is generally made before the year during which the migrants settle in the host country. Although this justification is highly plausible, we conduct in the Appendix B-2 two robustness checks. First we include forward variables in our recursive identification scheme to take into account the role of anticipations. Second, we propose an alternative identification strategy using sign restrictions. The results reported in Appendix Figure B-1 (and Table B-1) and Figure B-2 (and Table B-2) reveal impulse responses that are roughly the same as the estimation of our baseline model reported in Figure 2 (and in Appendix Table B-1).

\subsection{Demographic Benefit of Immigration}

Our claim is that the economy's positive responses to migration shocks can be explained by a demographic dividend of international migration. Because many of them are of working age, migrants tend to boost the share of the workforce in the OECD countries and can be a source of economic growth. We initially test this idea by extending our baseline model to analyze the response of the share of working-age population to a migration shock. Then, we investigate the results by decomposing the GDP per capita to disentangle the effects of international migration on the workforce. 
We initially consider the following system (referred to below as Model 2) $Z_{i t}^{2}=$ $\left[m_{i t}, w a_{i t}, g_{i t}, n t_{i t}, y_{i t}\right]^{\prime}$, where $w a$ is the logarithm of the ratio of working-age to total population (see Appendix A-3 for more details). The impulse response functions to migration shock are presented in Appendix Table B-7-(a). Consistent with our intuition, the ratio of working-age to total population significantly increases after a migration shock from the year of that shock and for at least 4 years. Because the ratio of working-age to total population is a component of GDP per capita, we now move one step further by decomposing the GDP per capita into two components: the ratio of working-age to total population and the GDP per working-age population. We thus consider the following system (Model 3): $Z_{i t}^{3}=\left[m_{i t}, w a_{i t}, g_{i t}, n t_{i t}, \tilde{y}_{i t}\right]^{\prime}$ where $\tilde{y}$ is the logarithm of the GDP per working-age population. The impulse response functions to a migration shock are presented in Figure 4 and in Appendix Table B-7- $(b)$. Both the ratio of working-age to total population and GDP per working-age population significantly increase after a migration shock. The responses of fiscal variables are roughly unchanged compared with our baseline model.

To disentangle the effects of international migration on the workforce, we thus pursue our investigation by considering the decomposition of the GDP per capita into three components: the ratio of working-age to total population, the ratio of total employment to the working-age population (namely the employment rate) and the GDP per person employed (labor productivity according to national accounts). We estimated the following system (Model 4): $Z_{i t}^{4}=\left[m_{i t}, w a_{i t}, g_{i t}, n t_{i t}, p d t y_{i t}, e r_{i t}\right]^{\prime}$ where $p d t y$ and $e r$ are respectively the logarithms of labor productivity and employment rate (see Appendix A-3 for more details). The impulse response functions to migration shock are presented in Figure 5 and in Appendix Table B-7-(c). The employment rate significantly increases after a migration shock from the year of that shock and remains significant for at least 7 years. The response of labor productivity was not significant during the 4 years after the migration shock and became negative from the 5th year after the shock. The positive response of the GDP per capita to a migration shock obtained in our baseline specification is thus driven by the demographic effect that materialized through an increase in the share of working-age 
Figure 4: Responses to a migration shock in the model with share of working-age population and GDP per working-age population
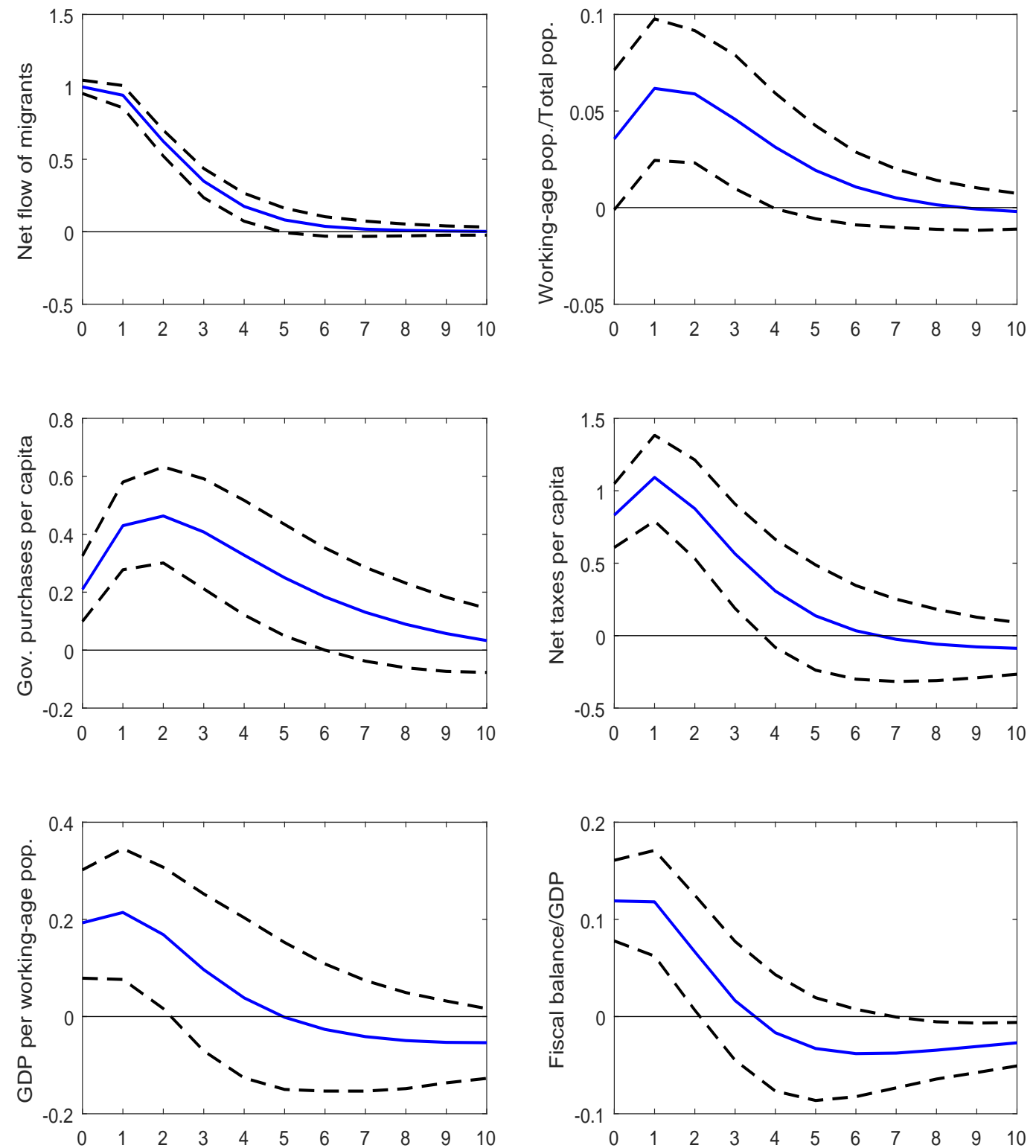

Notes: This figure refers to Model 3. The solid line gives the estimated impulse responses. Dashed lines give the $90 \%$ confidence intervals generated by Monte Carlo with 5000 repetitions. The responses of net flow of migrants are in per 1000 points change. For per capita variables, the responses are in percentage change. For the ratios of both the working-age to total population and of the fiscal balance to GDP, the responses are in percentage points change.

population and a positive response of the employment rate. 
Figure 5: Responses to a migration shock in the model with share of working-age population, labor productivity and employment rate
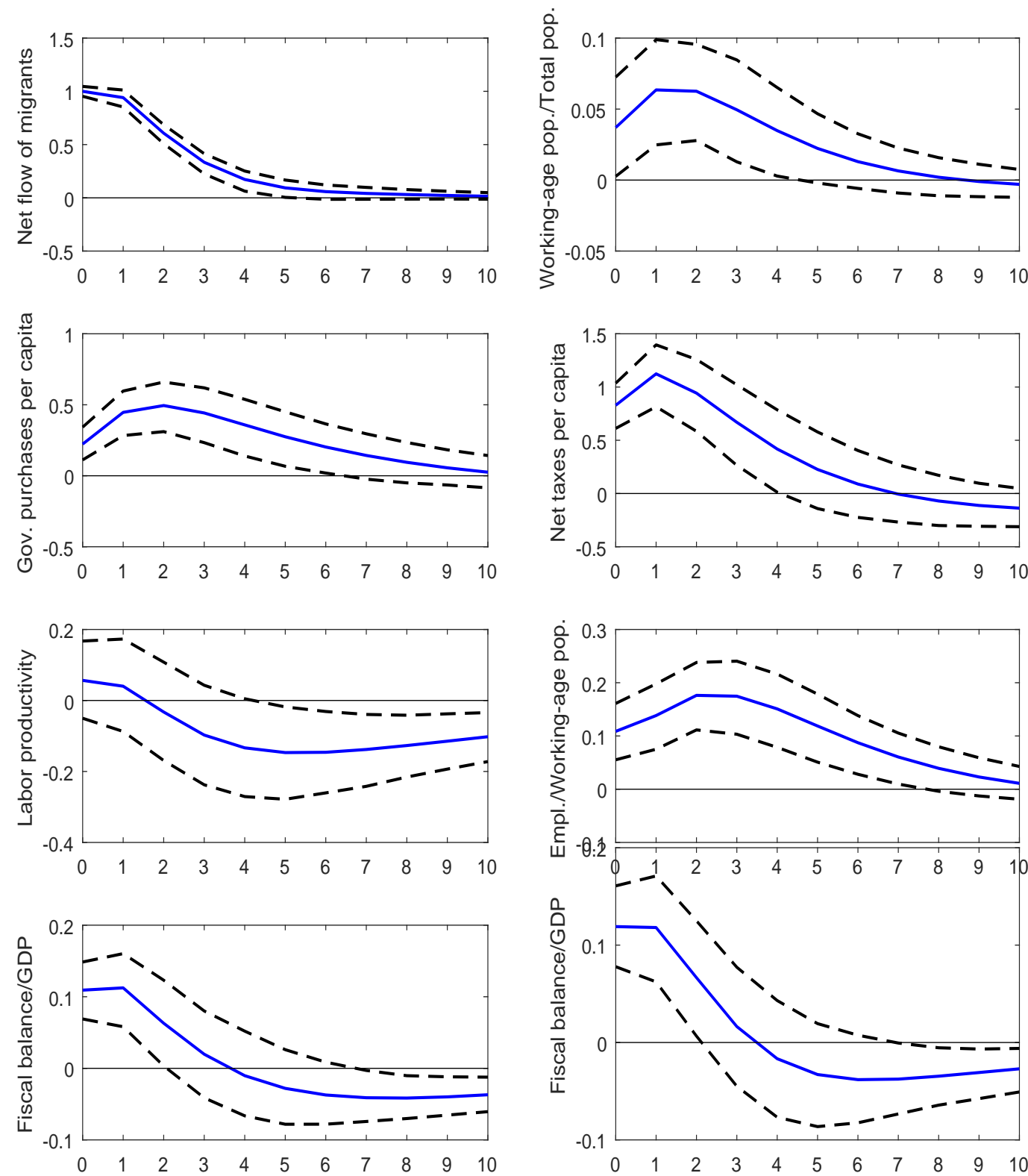

Notes: This figure refers to Model 4. The solid line gives the estimated impulse responses. Dashed lines give the $90 \%$ confidence intervals generated by Monte Carlo with 5000 repetitions. The responses of net flow of migrants are in per 1000 points change. For per capita variables, the responses are in percentage change. For the ratios of, working age to total population, total employment to working-age population and the fiscal balance to GDP, the responses are in percentage points change. 


\subsection{Immigration and the Age Structure of Public Spending}

The increase in the workforce due to international migration producing a demographic dividend, which we have highlighted in the baseline model. Because we also find a positive response of the fiscal balance to a migration shock, those beneficial effects of the demographic dividend of international migration appear to be related to the social public policies in place in the OECD countries. More precisely, we expect that net flows of migrants contribute to the financing of intergenerational public transfers. We develop this idea with various decompositions of the fiscal variables.

We first estimated an extension of our baseline model by breaking up the net taxes to analyze the response of the transfers paid by the general government to a migration shock. We consider the following system (Model 5): $Z_{i t}^{5}=\left[m_{i t}, g_{i t}, t r_{i t}, r e_{i t}, y_{i t}\right]^{\prime}$ where $t r$ and $r e$ are, respectively, the logarithms of per capita; transfers paid and tax revenues received by the general government (see Appendix A-3 for more details). The impulse response functions to migration shock are presented in Figure 6 and in Appendix Table B-8- $(a)$. We also present the responses of the fiscal variables as share of GDP, which allows us to highlight the effect of migration shock and control for its positive effect on GDP. We observe that following a migration shock, the increase of net taxes per capita reported above can be explained both by an increase in tax revenues per capita (by $0.33 \%$ the year of the shock) and a decrease in transfers per capita ( $0.23 \%$ the year of the shock and by $0.20 \%$ one year after the shock). As a share of GDP, we observe that the magnitude of the effects is reduced, which was expected, but that responses remain significant.

Because many of them are of working age and possibly arrive with children, one thus expects that the net flow of migrants reduces (in per capita terms) public spending dedicated to the elderly people but increases (in per capita terms) public spending dedicated to youth. As indicated in Appendix A-1, OECD Economic Outlook data do not provide details on government purchases or transfers that would allow the identification of the target population of the public spending. We therefore use SOCX data to analyze the effect of international migration on the age structure of public spending.

More precisely, we are interested in public expenditures dedicated to the old-age 
Figure 6: Responses to migration shock in the model with gov. purchases, transfers and revenues
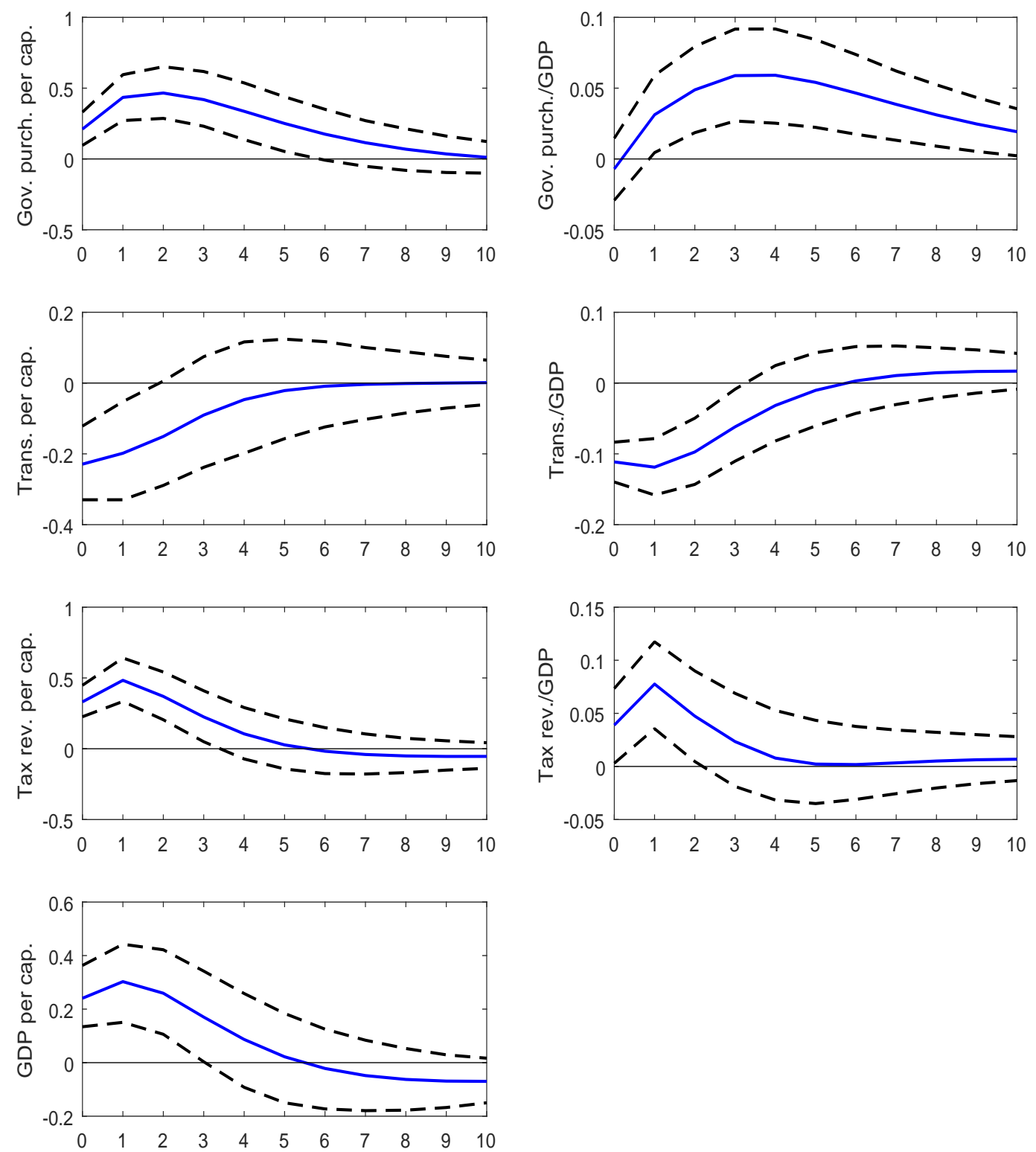

Notes: This figure refers to Model 5. The solid line gives the estimated impulse responses. Dashed lines give the $90 \%$ confidence intervals generated by Monte Carlo with 5000 repetitions. For per capita variables, the responses are in percentage change; for variables as a share of GDP, the responses are in percentage points change.

population and those dedicated to the youth population. These expenditures can be found in both the transfers paid by the government and the government purchases. Thus, before proposing a decomposition by age structure, we group those two components of government expenditures in one variable named public spending. The baseline model is thus rewritten as follows (Model 6): $Z_{i t}^{6}=\left[m_{i t}, p s_{i t}, r e_{i t}, y_{i t}\right]^{\prime}$ where ps represents for 
the logarithm of per capita public spending (including transfers). The impulse response functions to a migration shock are presented in Figure 7 and in Appendix Table B-8 - $(b)$. We observe that our previous results are not modified. Interestingly, public spending, when computed as a share of GDP, significantly decreases in the year of the migration shock, which is due to a non-significant increase in public spending including transfers that is dominated by a significant increase in GDP the year of the migration shock.

Figure 7: Responses to a migration shock in the model with public spending and revenues
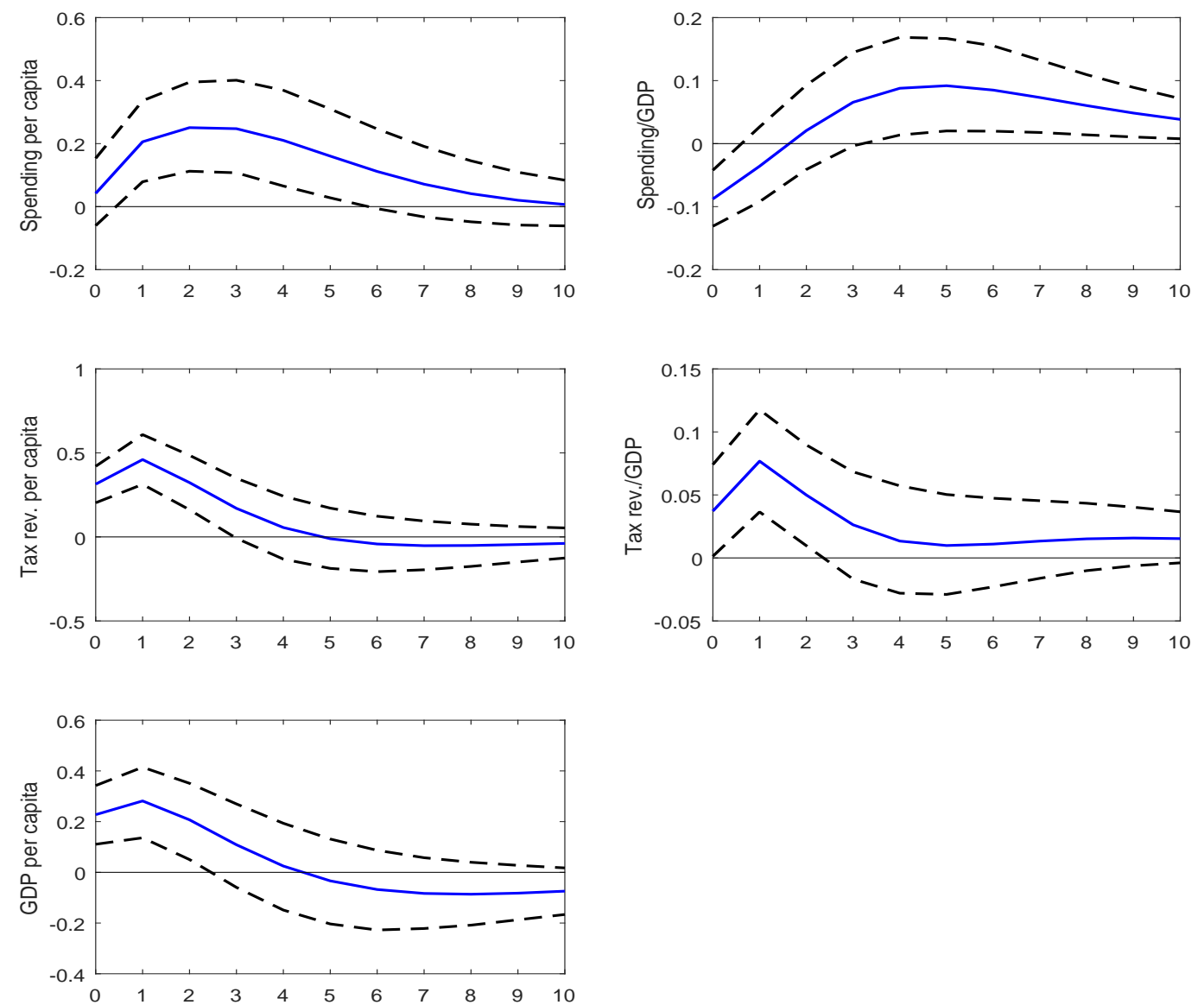

Notes: This figure refers to Model 6. The solid line gives the estimated impulse responses. Dashed lines give the $90 \%$ confidence intervals generated by Monte Carlo with 5000 repetitions. For per capita variables, the responses are in percentage change; for variables as a share of GDP, the responses are in percentage points change.

We now consider in the model including public spending and tax revenues, the effect of the net flow of migrants on social public expenditures dedicated to the youth population (family spending) and those expenditures dedicated to the old-age population (old-age spending). We estimated two additional models (Models 7 and 8, respectively): 
$Z_{i t}^{7}=\left[m_{i t}, p s_{i t}, f s_{i t}, r e_{i t}, y_{i t}\right]^{\prime}$ and $Z_{i t}^{8}=\left[m_{i t}, p s_{i t}, o a s_{i t}, r e_{i t}, y_{i t}\right]^{\prime}$, where $f s$ and oas are respectively the logarithms of per capita; family spending and old-age spending (see Appendix A-3 for more details). Our estimates are reported in Figure 8 and in Appendix Table B-8, panels $(c)$ and $(d)^{14}$. We observe that family spending significantly increases a few years after a migration shock, whether they are computed in per capita or as a share of GDP. Conversely, old-age spending significantly decrease after a migration shock. When computed as a share of GDP, the decrease is significant as early as the year of the migration shock but it is delayed until 3 years after the shock when old-age spending are computed in per capita terms.

Two main conclusions can be drawn from these estimates. First, our results are consistent with basic intuition, which constitutes an additional validation of our econometric model. Second, our results suggest that the demographic dividend of international migration goes through public finances. The cost induced by the increase in family spending is more than compensated for by the benefits of international migration and most notably for the financing of public pension systems.

\subsection{Immigration and Labor Market Public Spending}

An important issue in OECD countries is the effect of international migration on labor market conditions. We thus go beyond our baseline model to now consider the fiscal implications of a net flow of migrants while explicitly taking into account the labor market.

We extend our baseline model including the unemployment rate in the system as follows (Model 9): $Z_{i t}^{9}=\left[m_{i t}, g_{i t}, n t_{i t}, y_{i t}, u_{i t}\right]^{\prime}$, where $u$ is the logarithm of the unemployment rate. The corresponding results are presented in Appendix Table B-9-(a). Second, we estimate an additional model with public spending, tax revenues and unemployment rate (Model 10): $Z_{i t}^{10}=\left[m_{i t}, p s_{i t}, r e_{i t}, y_{i t}, u_{i t}\right]^{\prime}$. The corresponding impulse response functions are presented in Figure 9 and in Appendix Table B-9-(b). We observe that effects

\footnotetext{
${ }^{14}$ Note that due to the shorter data availability of detailed SOCX data, the estimation sample covers the 19 OECD countries over the period 1990-2013 for the models including family spending and old-age spending, respectively. See Appendix A for more details.
} 
Figure 8: Age-related public spending responses to migration shock

(a) Family spending responses
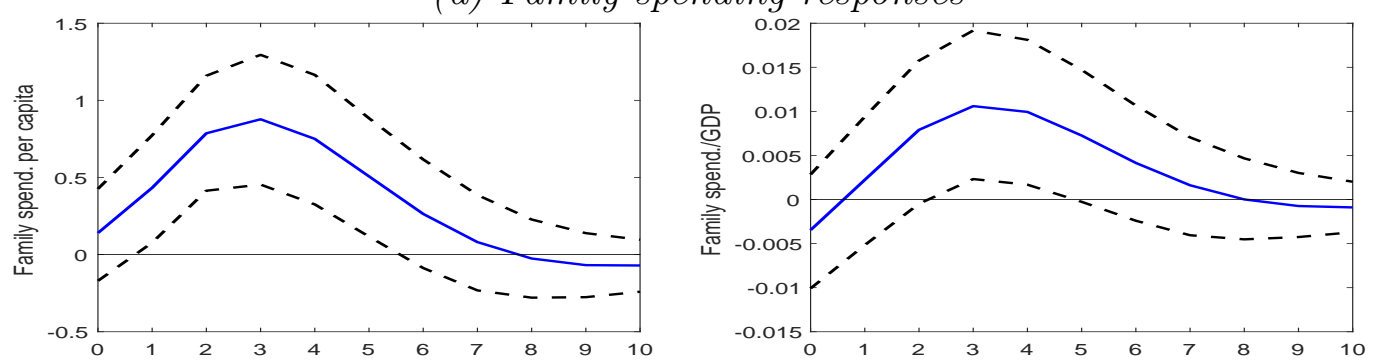

(b) Old-age spending responses
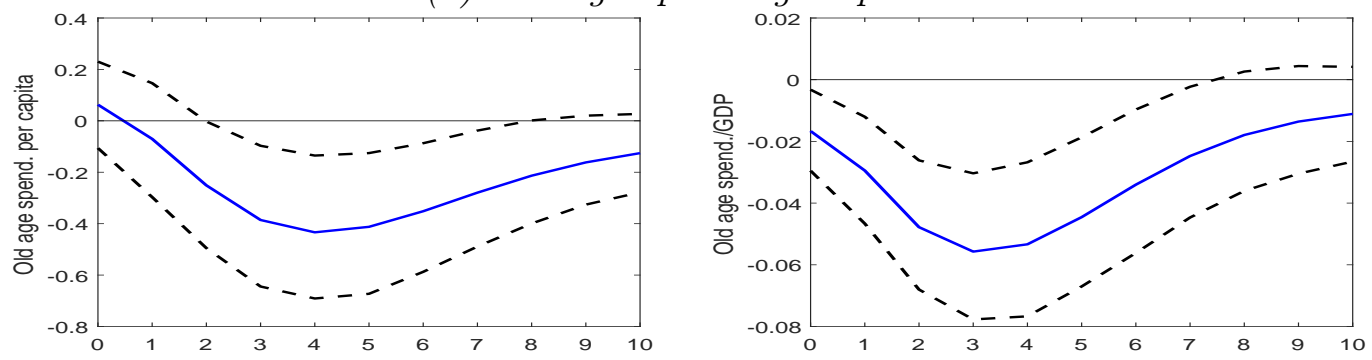

Notes: This figure refers to Models 7 and 8 respectively. The solid line gives the estimated impulse responses. Dashed lines give the $90 \%$ confidence intervals generated by Monte Carlo with 5000 repetitions. For per capita variables, the responses are in percentage change; for variables as a share of GDP, the responses are in percentage points change.

on both GDP per capita and fiscal variables are roughly unchanged compared with our baseline model including the unemployment rate. Interestingly, we observe that a migration shock significantly reduces the unemployment rate by 0.1 percentage points the year of the shock and for two years after the shock. This observation confirms the previous findings we obtained for 15 Western European countries (d'Albis et al., 2018) and those obtained by Furlanetto and Robstad (2016). These findings are also consistent with previous empirical studies such as Damette and Fromentin (2013) and Gross (2002). Damette and Fromentin (2013) estimated a vector error correction Model (VECM) on a panel of 14 OECD countries. They found that immigration negatively influences the level of unemployment in the short term. Gross (2002) estimated a VAR model to investigate the effect of the flows of migrants on the French labor market over the 1975Q1-1994Q4 period. She showed that the arrival of migrants decreases the unemployment rate permanently.

Then, we extended the model further, with public spending, tax revenues and unemployment rate, by considering public spending on labor market policies. Using SOCX data 
Figure 9: Responses to migration shock model with public spending, revenues and unemployment rate
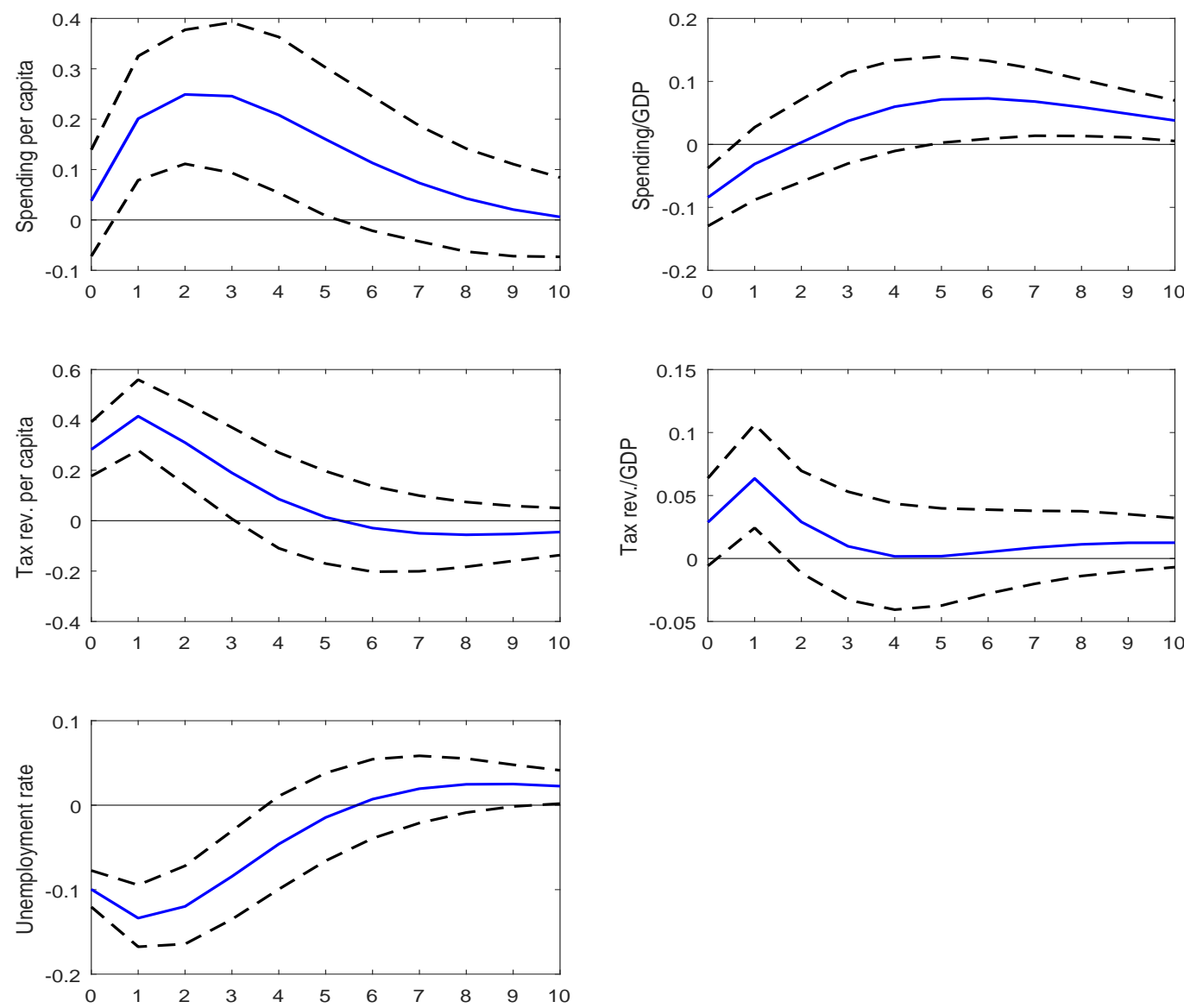

Notes: This figure refers to Model 10. The solid line gives the estimated impulse responses. Dashed lines give the $90 \%$ confidence intervals generated by Monte Carlo with 5000 repetitions. For per capita variables, the responses are in percentage change; for variables as a share of GDP, the responses are in percentage points change. For unemployment rate, the responses are in percentage points change.

decomposition of public expenditures, we studied the effect of a migration shock considering the SOCX data social policy areas related to the labor market: active labor market programs and unemployment ${ }^{15}$. We estimated two additional models (Models 11 and 12, respectively): $Z_{i t}^{11}=\left[m_{i t}, p s_{i t}, a l s_{i t}, r e_{i t}, y_{i t}, u_{i t}\right]^{\prime}$ and $Z_{i t}^{12}=\left[m_{i t}, p s_{i t}, u s_{i t}, r e_{i t}, y_{i t}, u_{i t}\right]^{\prime}$, where als and us represent respectively the logarithms of per capita; active labor market programs spending and unemployment spending (see Appendix A-3 for more details). The corresponding impulse response functions are presented in Figure 10 and in Appendix Table B-9, panels $(c)$ and $(d)^{16}$. We observe that, following a migration shock,

\footnotetext{
${ }^{15}$ See Adema et al. (2011) for the methodological aspects of the OECD SOCX data.

${ }^{16}$ Note that due to the shorter data availability of detailed SOCX data, the estimation sample covers
} 
per capita spending on active labor market programs increase (by $1.49 \%$ the year of the shock) whereas per capita spending associated with unemployment benefits decrease (by $1.71 \%$ the year of the shock). These results interestingly clarify the effects of a net flow of migrants shock on the labor market. As newcomers, migrants are necessarily more likely to benefit from a public support during their job search, which represents a cost for public finances. However, because of their contribution to the reduction of the unemployment rate, migrants do reduce expenditures associated with unemployment benefits. All in all, public spending on labor market policies decrease after a migration shock.

Figure 10: Labor market public spending responses to migration shock (a) Active labor programs spending responses
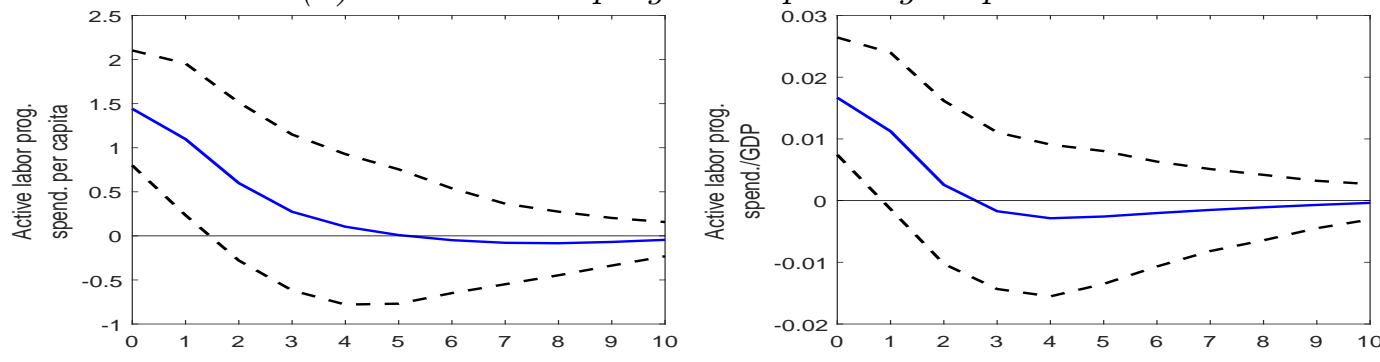

(b) Unemployment spending responses
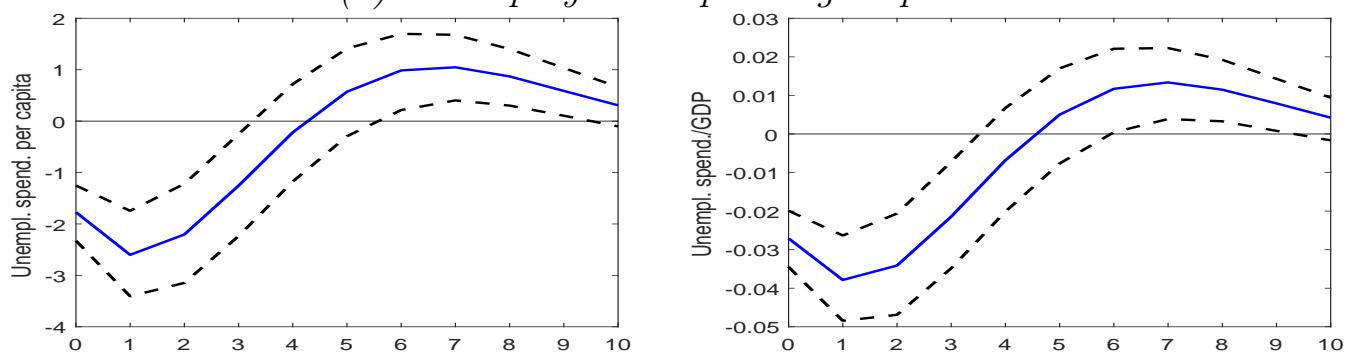

Notes: This figure refers to Models 11 and 12 respectively. The solid line gives the estimated impulse responses. Dashed lines give the $90 \%$ confidence intervals generated by Monte Carlo with 5000 repetitions. For per capita variables, the responses are expressed in percentage change; for variables as a share of GDP, the responses are in percentage points change.

the 19 OECD countries over the period 1990-2013 for the model, including active labor market programs spending. Denmark is not considered in the estimation of the model including unemployment spending. For this model, the estimation sample covers the 18 OECD countries over the period 1990-2013. See Appendix A for more details. 


\section{Theoretical Analysis}

To understand our econometric results, we build an overlapping-generations model that aims at theoretically analyzing the effect of a migration shock on income per capita and on public finances. With a stylized model, we focus our analysis on contemporaneous and delayed effects of international migration on income and net taxes.

\subsection{An Overlapping-Generation Framework}

We consider a demographic structure with three overlapping generations. An agent is successively a child, a worker and an old person, and there is no mortality across these age classes. Migrants enter the population during adulthood and have the same fertility rate as that of the native population. This set of assumptions allows the model to remain analytically tractable. We believe that the results obtained below with this simple structure extend to more general frameworks that would allow for many generations, uncertain survival probabilities and differential fertility rates.

The demographic model distinguishes stock variables, namely the size of each age class at the beginning of the period, and flow variables, given by newborns and migrants that enter the population during the period. The stock of native workers at the beginning of period $t$ is denoted by $N_{w t}$, and the net flow of migrants is denoted by $I_{t}=\lambda_{t} N_{w t}$, where $\lambda_{t}>-1$ is thus the proportion of the net flow of migrants within the native working-age population. The total workforce during period $t$, denoted $L_{t}$, is therefore given by the following:

$$
L_{t}:=N_{w t}+I_{t}=\left(1+\lambda_{t}\right) N_{w t}
$$

The fertility rate of both natives and migrants is given by $\beta_{t}$, which implies that the flow of newborns during period $t$ is $\beta_{t}\left(1+\lambda_{t}\right) N_{w t}$. Therefore, the difference equations that describe the evolution of the working-age population and the elderly population, denoted $N_{o t}$, are given as follows, respectively:

$$
N_{w t+1}=\beta_{t}\left(1+\lambda_{t}\right) N_{w t},
$$


and

$$
N_{o t+1}=\left(1+\lambda_{t}\right) N_{w t}
$$

According to statistical standards, demographic and economic indicators are divided by the average population, which is computed by national statistics agencies and international organizations as average of the population at 1st January of two successive years. Following this convention, we therefore define and compute, using equations (6) and (7), the average population in $t$, denoted $P_{t}$, as follows:

$$
P_{t}:=\frac{N_{w t}+N_{o t}+N_{w t+1}+N_{o t+1}}{2}=\frac{\left[1+\left(1+\beta_{t}\right)\left(1+\lambda_{t}\right)\right] N_{w t}+N_{o t}}{2} .
$$

Using equations (5), (6), (7) and (8), the ratio of working-age to total population is equal to the following:

$$
\frac{N_{w t}+I_{t}}{P_{t}}=\frac{2\left(1+\lambda_{t}\right)}{1+\left(1+\beta_{t}\right)\left(1+\lambda_{t}\right)+\frac{1}{\beta_{t-1}}} .
$$

We observe that the migration rate has a positive effect on this ratio, whereas the fertility rate in $t$ has a negative impact in $t$ followed by a positive effect in $t+1$. Similarly, the population growth rate during period $t$, denoted $n_{t}$, is given by the following:

$$
1+n_{t}:=\frac{N_{w t+1}+N_{o t+1}}{N_{w t}+N_{o t}}=\left(1+\lambda_{t}\right) \frac{1+\beta_{t}}{1+\frac{1}{\beta_{t-1}}} .
$$

We observe that a positive shock on the migration rate at $t$ increases the growth rate in $t$, while a positive shock on the birth rate at $t$ increases the growth rate both in $t$ and $t+1$. When demographic parameters are constant, the growth rate is given by: $1+n=\beta(1+\lambda)$.

\subsection{Contemporaneous Effect of Immigration on Income per Capita}

We initially analyze the effect of a migration shock occurring in $t$ on income per capita in t. Our estimates reveal that, following a migration shock, GDP per capita significantly increases the year of the shock.

In the literature, a positive effect of international migration on income per capita 
was noted provided that the production function displays some complementarity between migrants and natives (Ottaviano and Peri, 2012) or increasing returns-to-scale (Lundberg and Segerstrom, 2002). Moreover, the economic effect of international migration can be positive if migrants bring physical or human capital with them (Boubtane et al., 2016). We consider here another channel in a framework that ignores all of those factors. We suppose perfect substitutability between migrants and natives, constant returns-to-scale, and migrants that come without capital.

The production in $t$ is described by the function $F\left(K_{t}, L_{t}\right)$, where $K_{t}$ is the stock of capital installed at the beginning of period $t$, which is thus not affected by the net flow of migrants. Function $F(.,$.$) satisfies the usual neoclassical properties: it is homogeneous$ of degree 1 and is increasing and concave with respect to each argument. As we noted above, the convention in empirical studies is to use the average population $P_{t}$ to calculate income per capita, denoted here $y_{t}$. Using (5), (8) and (9), we obtain income per capita and write it as the product of the labor productivity and the ratio of working-age to total population:

$$
y_{t}:=\frac{F\left(K_{t},\left(1+\lambda_{t}\right) N_{w t}\right)}{P_{t}}=\frac{F\left(k_{t},\left(1+\lambda_{t}\right)\right)}{\left(1+\lambda_{t}\right)} \frac{2\left(1+\lambda_{t}\right)}{\left[1+\left(1+\beta_{t}\right)\left(1+\lambda_{t}\right)\right]+\frac{1}{\beta_{t-1}}},
$$

where $k_{t}:=K_{t} / N_{w t}$ represents the capital per population of native workers, which does not depend upon the migration rate $\lambda_{t}$. From (11), we observe that a migration shock reduces labor productivity and increases the ratio of working-age to total population. The final result is thus ambiguous. We obtain the following result:

Proposition 1 A migration shock in $t$ has a positive effect on income per capita in $t$ if and only if:

$$
\frac{L_{t} F_{L}^{\prime}\left(K_{t}, L_{t}\right)}{K_{t} F_{K}^{\prime}\left(K_{t}, L_{t}\right)} \geq 1+n_{t}
$$

Proof. See the Appendix.

Proposition 1 states that a net flow of migrants has a positive effect on income per capita if the ratio of factor shares in output is greater than the population growth factor. 
We notice that the ratio varies from one country to another but is likely to be larger than one and is equal to 2 when the share of wages in output is $2 / 3$. We also observe that the net flow of migrants is more likely to be favorable to the economy when the population growth rate is low, which is a common feature of aging populations.

It should be stressed that the length of a period here is approximately 30 years, which is approximately the duration of a generation. Nevertheless, our result can be easily extended to an overlapping-generations model with periods whose lengths are one year as in the empirical part of this paper.

The result we provided can be understood by investigating further the definition of the population. In (8), we defined an average population following the standard definition used by national statistics agencies and international organizations. However, we notice that income per capita would have been written as follows:

$$
y_{t}^{\text {begin }}=\frac{F\left(k_{t},\left(1+\lambda_{t}\right)\right)}{1+\frac{N_{o t}}{N_{w t}}}
$$

if population were evaluated at the beginning of the period, whereas it would have been written as follows:

$$
y_{t}^{e n d}=\frac{F\left(\frac{k_{t}}{\left(1+\lambda_{t}\right)}, 1\right)}{\left(1+\beta_{t}\right)},
$$

if population were evaluated at the end of the period. Equations (13) and (14) reveal that $y_{t}^{\text {begin }}$ increases with the migration rate, $\lambda_{t}$, whereas $y_{t}^{\text {end }}$ decreases with $\lambda_{t}$. By using the average population definition, we thus obtained an intermediate result. A natural implication of these derivations is that estimates should be affected by the population definition that is used. We have thus reestimated our model using the population at 1st January and the population at 31 December. As shown in Appendix Figure B-3, the contemporaneous response is stronger for $y_{t}^{\text {begin }}$ than for $y_{t}^{\text {end }}$, as predicted by the theory above. The response of $y_{t}^{e n d}$ is not negative, which suggest that complementarities between natives and migrants might play a role as soon as migrants enter the labor market. This point also explains why we do not observe with the VAR model a decline in labor productivity at the date of the shock. 
The contemporaneous effect of a net flow of migrants on factor prices is easier to derive. Because wages in $t$ are given by $w_{t}=F_{L}^{\prime}\left(k_{t},\left(1+\lambda_{t}\right)\right)$, the relationship between migration rate and wages is negative due to decreasing marginal returns. For the interest rate, which is linearly related to $F_{K}^{\prime}\left(k_{t},\left(1+\lambda_{t}\right)\right)$, the relationship is given by the sign of the cross-derivative of the production function, which implies that the contemporaneous effect of a migration shock is positive.

\subsection{Government Budget}

We now turn to the main equation defining the government budget, which is here assumed to be balanced. The budget features two sources of expenses dedicated respectively to young and old populations, which are financed through taxes on labor income. The expense dedicated to youth is an in-kind transfer, such as preschool institutions, whereas the expense dedicated to the elderly is an in-cash transfer, such as a public pension. Let $\tau_{t}, \pi_{t}$ and $\kappa_{t}$ denote the tax rate, the expense per elderly person and the expense per child, respectively. The government budget is balanced if the following holds:

$$
\tau_{t} w_{t}\left(1+\lambda_{t}\right) N_{w t}=\pi_{t} N_{o t}+\kappa_{t} \beta_{t}\left(1+\lambda_{t}\right) N_{w t}
$$

Everything else equal, we observe from (15) that an increase in the migration rate in $t$ increases both fiscal revenues and expenses dedicated to youth. Let us now suppose that public expenditure per person, in the form of expenses dedicated respectively to old and youth populations, are proportional to the current wages, such that $\pi_{t}=\pi w_{t}$ and $\kappa_{t}=\kappa w_{t}$, where $\pi \in[0,1)$ represents a pension replacement rate and where $\kappa \in[0,1)$.

We also assume that the tax rate is chosen to balance the budget. Therefore, using (6) and (7), the tax rate is given by the following:

$$
\tau_{t}=\frac{\pi}{\left(1+\lambda_{t}\right) \beta_{t-1}}+\kappa \beta_{t}
$$

The tax rate positively depends upon rates $\pi$ and $\kappa$, and on demographic parameters. We observe that a migration shock in $t$ has a negative effect on $\tau_{t}$, whereas a fertility 
shock in $t$ has a positive effect on $\tau_{t}$ followed by a negative effect on $\tau_{t+1}$. This difference is explained by the fact that migrants enter the population as working age persons.

In this framework, net taxes, defined as tax revenues minus transfers, can be written in per capita terms as follows:

$$
\frac{\kappa w_{t} \beta_{t}\left(1+\lambda_{t}\right) N_{w t}}{P_{t}}=\frac{2 \kappa w_{t} \beta_{t}}{\frac{\left(1+\beta_{t-1}\right)}{\beta_{t-1}\left(1+\lambda_{t}\right)}+\left(1+\beta_{t}\right)} .
$$

Therefore, the effect of a migration shock in $t$ on net taxes per capita in $t$ is a priori ambiguous: on the one hand, the ratio of those of working age to total population increases, which tends to raise net taxes per capita. On the other hand, wages decrease, which tends to decreases net taxes per capita. According to our estimates presented in Figure 2, the contemporaneous effect of a migration shock on net taxes per capita is significantly positive, which suggests that the demographic benefit of migration dominates the potentially negative wage effect.

\subsection{Effect of a Migration Shock in a Dynamic Model}

We now analyze the consequences of a migration shock on savings and capital accumulation in a model that incorporates the demographic structure and the government budget described above. The saving rate is the solution of the consumer's optimization problem. An agent born in $t-1$ maximizes consumption when working age and old age, denoted $c_{w t}$ and $c_{o t+1}$ respectively. Without loss of generality, consumption during childhood is not considered here ${ }^{17}$. During working age, the agent distributes her net wages toward consumption and savings, the latter denoted $s_{t}$. During old age, the agent consumes her savings income, denoted $R_{t+1} s_{t}$, where $R_{t+1}$ is the interest on savings or capital accumulation, and the transfers she receives from the government. The optimization problem

\footnotetext{
${ }^{17}$ Equivalently, we could have supposed that such consumption is proportional to that of their parents.
} 
can be written as follows:

$$
\begin{array}{c|l}
\max _{\left\{c_{w t}, c_{o t+1}\right\}} \ln c_{w t}+\theta \ln c_{o t+1}, \\
s . t . & c_{w t}=\left(1-\tau_{t}\right) w_{t}-s_{t}, \\
& c_{o t+1}=R_{t+1} s_{t}+\pi_{t+1},
\end{array}
$$

where $\theta>0$. The optimal savings rate satisfies the following:

$$
s_{t}=\frac{1}{1+\theta}\left[\theta\left(1-\tau_{t}\right) w_{t}-\frac{\pi_{t+1}}{R_{t+1}}\right] .
$$

By replacing the tax rate that balances the budget, given by (16), in the latter expression, we obtain that the optimal savings can be rewritten as follows:

$$
s_{t}=\frac{1}{1+\theta}\left[\theta\left(1-\frac{\pi}{\left(1+\lambda_{t}\right) \beta_{t-1}}-\kappa \beta_{t}\right) w_{t}-\frac{\pi w_{t+1}}{R_{t+1}}\right]
$$

Migration rate influences savings through two opposing channels in our model; in $t$, it decreases wages but also decreases net taxes. With (19), we also observe that future factor prices play a role that can be evaluated by studying the general equilibrium of the model.

For consistency purposes, we assume that the tax rate is less than 1 by imposing an upper bound on the replacement rate $\pi$. We assume the following:

$$
\pi<\pi_{t}^{\text {sup }}:=\left(1-\kappa \beta_{t}\right)\left(1+\lambda_{t}\right) \beta_{t-1}
$$

This condition is necessary to have positive savings.

In overlapping-generations models, the capital stock in the next period equals the aggregate savings of the current period such that $K_{t+1}=s_{t} L_{t}$. Assuming a Cobb-Douglas production function $K_{t}^{\alpha} L_{t}^{1-\alpha}$, where $\alpha \in(0,1)$, and a capital depreciation rate of 1 , we 
obtain the following difference equation that describe the dynamics of the $k_{t}$ :

$$
k_{t+1}=\frac{\theta\left(1-\frac{\pi}{\left(1+\lambda_{t}\right) \beta_{t-1}}-\kappa \beta_{t}\right)(1-\alpha)}{\left[\beta_{t}(1+\theta)+\frac{\pi(1-\alpha)}{\alpha\left(1+\lambda_{t+1}\right)}\right]\left(1+\lambda_{t}\right)^{\alpha}} k_{t}^{\alpha},
$$

with $k_{0}$ given. Provided that condition (20) is satisfied, there exists a temporary equilibrium. Moreover, once demographic parameters $\left(\lambda_{t}, \beta_{t}\right)$ are constant, $k_{t}$ monotonously converges to a steady-state. The total effect of a migration shock on $k_{t}$ in the next period is given in the following proposition.

Proposition 2 There exists a unique $\bar{\pi}_{t} \in\left(0, \pi_{t}^{\text {sup }}\right)$ such that a migration shock in $t$ has a positive effect on $k_{t}$ in $t+1$ if and only if $\pi \geq \bar{\pi}_{t}$. Moreover, $\bar{\pi}_{t}$ decreases with $\kappa$.

Proof. See the Appendix.

Proposition 2 states that there exists a replacement rate above which a migration shock has a positive effect on $k_{t}$ in the following period. This threshold depends upon time if the demographic parameters $\left(\lambda_{t}, \beta_{t}\right)$ change with time. The intuition can be easily given with equation (21), which reveals that a migration shock (i) necessarily reduces future capital stock if the replacement rate is zero and (ii) is more likely to have a positive effect if the replacement rate is large. Migrants are beneficial to the economy when pensions constitute a large part of public expenditure. Moreover, Proposition 2 establishes that the threshold decreases with the public expenditure dedicated to the youth. Everything else equal, a larger $\kappa$ is associated with a lower saving rate, which implies that the dilution effect of a migration shock is proportionally less important. In a nutshell, net flow of migrants is likely to have a positive effect on $k_{t}$ if public expenses dedicated respectively to youth and old populations are sufficiently large.

Proposition 2 is useful to ascertain what the effect of a migration shock would be. For instance, one might want to study the effect of a shock, defined as: $\lambda_{0}>\lambda$ and $\lambda_{t}=\lambda$ for all $t \geq 1$, on the economy at steady state. According to Proposition 2 and to the stability property of the steady state defined using (21), the $k_{t}$ would initially increase and then converge back to the steady state if $\pi>\bar{\pi}$. More precisely, the $k_{t}$ would satisfy the 
dynamics starting at $k_{0}$, such that $k_{1}>k_{0}, k_{2}>k_{0}, k_{3} \in\left(k_{0}, k_{2}\right)$, and so on. Conversely, if $\pi<\bar{\pi}$, the $k_{t}$ will decrease in $t=1$ and then increase to converge back to the steady state.

Proposition 3 Consider an economy at steady-state characterized by demographic parameters $(\beta, \lambda)$ and by $\pi>\bar{\pi}$. A migration shock satisfying $\lambda_{0} \in\left(\lambda, \frac{(1-\alpha)}{\alpha \beta}-1\right)$ and $\lambda_{t}=\lambda$ for all $t=1,2,$. induces: (i) an increase in income per capita for all $t=0,1, .$. and (ii) an increase in net taxes for all $t=0,1, \ldots$ Moreover, as of $t=2$, income per capita and net taxes converge back to their steady-state values.

Proof. See the Appendix.

Proposition 3 details the dynamic effect of a migration shock on the key variables of the economy. The focus here is on the positive effects of a net flow of migrants to be consistent with our empirical findings, but we obviously obtain the symmetric dynamics if the conditions are not satisfied. The theoretical responses of income per capita and net taxes per capita are qualitatively similar to those responses found in Figure 2.

Proposition 3 highlights two main transmission channels of the shock on the economy, characterizing the demographic dividend of international migration. The first effect is the increase in the relative size of the workforce, which can cancel out the dilution effect induced by the assumption of constant returns-to-scale in the production function. We observe that the effect is positive provided that the migration shock is not too large. As we mentioned with Proposition 1, this first transmission channel affects the economy at the date of the shock. Thus, income per capita increases but wages decrease. Interestingly, net taxes increase as the increase in the tax base counterbalances the wage reduction.

The second effect is due to a possible increase in the savings rate. As we seen with Proposition 2, this possibility relies on conditions that are assumed in Proposition 3. Through this channel, there is an increase in capital that positively affects income per capita, wages and net taxes one period after the shock, once savings are transformed into capital. Then, convergence after two periods occurs because we do not assume, to simplify the analysis, any persistence in the shock. The empirical analysis presented above 
reveals that migration shocks display some persistence, which will shape the response of the economy to the shock.

The effect of a permanent change in the migration rate is not analyzed here, because it is beyond the scope of the paper. It is, nevertheless, relatively simple to study and relies on the same conditions expressed above. Provided that $\pi>\bar{\pi}$, the steady state value of the $k_{t}$ increases, and we observe a monotonic convergence to the new steady-state.

To keep the theoretical analysis tractable, we have not considered here either the possibilities of fiscal deficits or the existence of unemployment as we did in our empirical analysis. Those developments are left for future research, but we can try to develop some basic arguments. Allowing for an unbalanced budget would most likely reinforce our results. At the date of the migration shock the fiscal balance would be improved, because the left-hand-side of the equation would decrease. This decrease would induce a reduction in the public debt that would reinforce an increase in saving, which is beneficial to capital accumulation. Allowing for unemployment is more challenging because doing so requires developing a relevant framework for analyzing labor market inefficiencies. Moreno-Galbis and Tritah (2016) use a search and matching model to show that immigrants increase employment rates of the natives. In our theoretical model, this increase would further increase taxes paid by workers and their savings, which in turn would improve the fiscal balance and income per capita.

\section{Conclusion}

In this paper, the fiscal effect of a net flow of migrants on the government budgets of OECD countries are quantified using a VAR approach consistent with previous studies on fiscal multipliers and interpreted with an overlapping-generation model. The results show that OECD countries, by virtue of their demographic structures and large public transfers to their non-working cohorts, constitute a group of countries in which international migration most likely yields a demographic dividend. In particular, a net flow of migrants has been shown to increase both GDP per capita and fiscal balance by increas- 
ing the share of the workforce and reducing per capita transfers. Our results are robust to various alternative assumptions, which suggests that the belief that public finances would be deteriorated by international migration was not observed for OECD countries over the period 1980-2015.

Given the restricted time-frame of our data, the results do not apply to any single country but show the average response of the 19 OECD countries we consider in our sample. Furthermore, the linear structure of the empirical model implies that these results only apply to "small" shocks and cannot be used to anticipate the effect of large flows of migrants.

Our research can be extended in various directions. First, the fiscal policy literature has recently discussed the existence -or absence- of state dependence on fiscal multipliers (Canzoneri et al., 2016). It could be interesting to determine whether the effects of international migration are state-dependent. Second, it would be useful to disaggregate the international migration. A breakdown between nationals and non-nationals would make it possible to more accurately assess the net contribution of migrants as defined in generational accounting studies. Unfortunately, this breakdown is not possible from the data currently available. Preliminary work on reconstructing migratory flow statistics is thus necessary. Finally, our stylized model could be extended to allow for fiscal deficits and unemployment. 


\section{Acknowledgments}

We are very grateful to the editor, Thomas A. Lubik, and two anonymous referees for their stimulating comments and helpful suggestions. We would like to thank Thepthida Sopraseuth, Omar Licandro, Frédéric Dufourt, and participants at the Theories and Methods in Macroeconomics (T2M) conference 2018 and the Sheffield Workshop on the Macroeconomics of Migration 2018 for discussion and useful comments on earlier drafts. The usual disclaimer applies.

\section{Finding}

This work was supported by the Agence Nationale de la Recherche of the French government through the Investissements d'avenir [ANR-10-LABX-14-01] program. 


\section{References}

Adema, W., Fron, P., Ladaique, M., 2011. Is the European welfare state really more expensive? Indicators on social spending, 1980-2012 and a manual to the OECD Social Expenditure Database (SOCX). OECD Social, Employment and Migration Working Papers No. 124.

Ager, P., Brückner, M., 2013. Cultural diversity and economic growth: Evidence from the US during the age of mass migration. European Economic Review 64, 76-97.

d'Albis, H., 2007. Demographic structure and capital accumulation. Journal of Economic Theory 132(1), 411-434.

d'Albis, H., Boubtane, E., Coulibaly, D., 2016. Immigration policy and macroeconomic performances in France. Annals of Economics and Statistics 121-122, 279-308.

d'Albis, H., Boubtane, E., Coulibaly, D., 2017. International migration and regional housing market: Evidence from France. International Regional Science Review, forthcoming.

d'Albis, H., Boubtane, E., Coulibaly, D., 2018. Macroeconomic evidence suggests that asylum seekers are not a burden for Western European countries. Science Advance 4: eaaq0883.

Alesina, A., Ardagna, S., Perotti, R., Schiantarelli, F., 2002. Fiscal policy, profits, and investment. American Economic Review 92, 571-589.

Auerbach, A., Oreopoulos, P., 1999. Analyzing the fiscal impact of US immigration. American Economic Review 89, 176-180.

Beaudry, P., Collard, F., 2003. Recent technological and economic change among industrialized countries: Insights from population growth. Scandinavian Journal of Economics $105(3), 441-464$.

Beetsma, R., Giuliodori, M., 2011. The effects of government purchases shocks: Review and estimates for the EU. The Economic Journal 121, F4-F32.

Beetsma, R., Giuliodori, M., Klaassen, F., 2006. Trade spill-overs of fiscal policy in the European Union: A panel analysis. Economic Policy 21, 639-687. 
Beetsma, R., Giuliodori, M., Klaassen, F., 2008. The effects of public spending shocks on trade balances and budget deficits in the European Union. Journal of the European Economic Association 6(2/3), 414-423.

Blanchard, O. J., Perotti, R., 2002. An empirical characterization of the dynamic effects change in government spending and taxes on output. Quarterly Journal of Economics $117,1329-1368$.

Blau, F. D., 1984. The use of transfer payments by immigrants. Industrial and Labor Relations Review 37(2), 222-239.

Blau, F. D., Mackie, C., 2016. The Economic and Fiscal Consequences of Immigration. A Report of the National Academies, Washington DC.

Bloom, D. E., Canning, D., Sevilla, J., 2003, The Demographic Dividend : a New Perspective on the Economic Consequences of Population Change Population Matters Monograh MR-1274, RAND, Santa Monica.

Boeri, T., 2010. Immigration to the land of redistribution. Economica 77, 651-687.

Boucekkine, R., de la Croix, D., Licandro, O., 2002. Vintage human capital, demographic trends, and endogenous growth. Journal of Economic Theory 104(2), 340-375.

Boubtane, E., Coulibaly, D., Rault, C., 2013. Immigration, growth and unemployment: Panel VAR evidence from OECD countries. Labour: Review of Labour Economics and Industrial Relations 27(4), 399-420.

Boubtane, E., Dumont, J. C., Rault, C., 2016. Immigration and economic growth in the OECD countries 1986-2006. Oxford Economic Papers 62, 340-360.

Brücker H., Capuano, S. and Marfouk, A., 2013. Education, gender and international migration: Insights from a panel-dataset 1980-2010, mimeo.

Brückner, M., Pappa, E., 2012. Fiscal expansions, unemployment, and labor force participation: Theory and evidence. International Economic Review 53, 1205-1228.

Canzoneri, M., Collard, F., Dellas, H., Diba, B., 2016. Fiscal multipliers in recessions. Economic Journal 126(590), 75-108.

Clemens, M. A., 2011 Economics and emigration: Trillion-dollar bills on the sidewalk? 
Journal of Economic Perspectives 25, 83-106.

Clemens, M. A., Hunt, J., 2017. The labor market effects of refugee waves: Reconciling conflicting results. NBER No. 23433.

Damette, O., Fromentin, V.2013. Migration and labour markets in OECD Countries: A panel cointegration Approach. Applied Economics 45, 2295-2304.

Dustmann, C., Frattini, T. 2014. The fiscal effects of immigration to the UK. Economic Journal 124, F593-643.

[dataset] European Social Survey Round 7 Data 2014. Data file edition 2.1. NSD - Norwegian Centre for Research Data, Norway Data Archive and distributor of ESS data for ESS ERIC.

Faust, J., 1998. The robustness of identified VAR conclusions about money. CarnegieRochester Conf. Ser. Public Policy 49, 207-244.

Fry, R. and Pagan, A. 2011. Sign restrictions in structural vector autoregressions: A critical review. Journal of Economic Literature 49 (4), 938-60.

Furlanetto, F., Robstad, Ø, 2016. Immigration and the macroeconomy: Some new empirical evidence. Norges Bank Working Paper 18/2016.

Gross, D. 2002. Three million foreigners, three million unemployed? Immigration flows and the labour market in France. Applied Economics 34, 1969-1983.

Hahn, J., Kuersteiner, G., 2002. Asymptotically unbiased inference for a dynamic panel model with fixed effects when both $\mathrm{n}$ and $\mathrm{T}$ are large. Econometrica 70, 1639-1657.

Juessen, F., Linnemann, L., 2012. Markups and fiscal transmission in a panel of OECD countries. Journal of Macroeconomics 34, 674-686.

Kiviet, J. F., 1995. On bias, inconsistency, and efficiency of various estimators in dynamic panel data models. Journal of Econometrics 68, 53-78.

Lee, R., Mason, A., 2007. Population aging, wealth, and economic growth: Demographic dividends and public policy. UN World Economic and Social Survey Background Paper.

Lee, R., Mason, A., members of the NTA network, 2014. Is low fertility really a problem? Population aging, dependency, and consumption. Science 346, 229-234. 
Lee, R., Miller, T., 1997. The Lifetime Fiscal Impacts of Immigrants and Their Descendants, in: The New Americans, National Research Council. Washington, DC: National Academy Press, 1997: 297-362.

Lee, R., Miller, T., 2000. Immigration, social security and broader fiscal impacts. American Economic Review 90, 350-354.

Leeper, E. M., Walker, T. B., Yang, S. C. S., 2013. Fiscal foresight and information flows. Econometrica 81, 1115-1145.

Lemaître, G., Liebig, T, Thoreau, C., 2006. Harmonised statistics on immigrant inflowspreliminary results, sources and methods. OECD, Paris.

Liebig, T. and Mo, J., 2013. The fiscal impact of immigration in OECD countries. International Migration Outlook, OECD Publishing.

Lundberg, P., Segerstrom, P., 2002. The growth and welfare effects of international mass migration. Journal of International Economics 56, 177-204.

Lütkepohl, H., 2005. New Introduction to Multiple Time Series Analysis. Springer.

Margolis D, Yassine C., 2015. Poverty, Employment and education in Southern Africa, 2020-2100. Mimeo, Labor Markets in Sub-Saharan Africa NJD 2015 SSA Regional Event, November 26-27, 2015; Cape Town, South Africa.

Massey, D. S., Pren, K. A., 2012. Unintended consequences of US immigration policy: Explaining the post-1965 surge from Latin America. Population and Development Review $38,1-29$.

Monacelli, T., Perotti, R., Trigari, A., 2010. Unemployment fiscal multipliers. Journal of Monetary Economics 57, 531-553.

Moreno-Galbis, E., Tritah, A., 2016. The effects of immigration in frictional labor markets: Theory and empirical evidence from EU countries. European Economic Review 84, 76-98.

National Research Council, 1997. The New Americans. Washington, DC: National Academy Press, 1997.

Nickell, S. J., 1981. Biases in dynamic models with fixed effects. Econometrica 49, 1417- 
1426.

[dataset] OECD, 2018a. Social Expenditure: Aggregated data (Edition 2017), OECD Social and Welfare Statistics.

[dataset] OECD, 2018b. Aggregate National Accounts, SNA 2008 (or SNA 1993): Gross domestic product, OECD National Accounts Statistics.

[dataset] OECD, 2017. Labour Force Statistics: Population and vital statistics (Edition 2017) OECD Employment and Labour Market Statistics.

[dataset] OECD, 2016. OECD Economic Outlook No. 99 (Edition 2016/1) OECD Economic Outlook: Statistics and Projections.

[dataset] OCDE, 2015, International Migration Database: OECD International Migration Statistics Database.

Ortega, J., Peri, G., 2014. Openness and income: The roles of trade and migration. Journal of International Economics 92, 231-251.

Ottaviano, G.I.P., Peri, G., 2012. Rethinking the effect of immigration on wages. Journal of the European Economic Association 10(1), 152-197.

Perotti, R., 2005. Estimating the effects of fiscal policy in OECD countries. CEPR Discussion.

Preston, I., 2014. The effect of immigration on public finances. The Economic Journal 124, F569-F592.

Price, R.W.R. Dang, T.-T., Botev, J. 2015. Adjusting fiscal balances for the business cycle: New tax and expenditure elasticity estimates for OECD countries. OECD Economics Department Working Papers, No. 1275.

Pope, D., Withers G. 1993. Do Migrants Rob Jobs? Lessons of Australian History, 18611991. Journal of Economic History 53, 719-742.

Rowthorn, R. 2008. The fiscal impact of immigration on the advanced economies. Oxford Review of Economic Policy 24(3), 560-580.

Sims, C. A., 1992. Interpreting the macroeconomic time series facts: The effects of monetary policy. European Economic Review 36, 975-1000. 
Smith, C., Thoenissen, C., 2018. Migration and business cycle dynamics. CAMA Working Papers 2018-20

Stock, J. H., Watson, M. W., 2001. Vector autoregressions. Journal of Economic Perspectives $15,101-115$.

Storesletten, K., 2000. Sustaining fiscal policy through immigration. Journal of Political Economy 108, 300-323.

Storesletten, K., 2003. Fiscal implications of immigration - a net present value calculation. Scandinavian Journal of Economics 105, 487-506.

Uhlig, H., 2005. What are the effects of monetary policy on output? Results from an agnostic identification procedure. Journal of Monetary Economics 52, 381-419.

United Nations, Department of Economic and Social Affairs, Population Division, 2015. International Migration Flows to and from Selected Countries: The 2015 Revision.

[dataset] United Nations, Department of Economic and Social Affairs. Population Division, 2017. Trends in International Migrant Stock: The 2017 revision (United Nations database, POP/DB/MIG/Stock/Rev.2017).

Yang, S., 2007. Tentative evidence of tax foresight. Economics Letters 96, 30-37. 


\section{Appendix}

\section{Appendix A Methods}

\section{A-1 Data}

We employ two main databases :

The OECD Economic Outlook database

The economic and fiscal variables are computed by using the following series codes from OECD (2016):

UNR: Unemployment rate

ET: Total employment

GDP, value: Gross domestic product at market prices

PGDP: Gross domestic product, deflator

CGAA: Government final consumption expenditure, value

PCG: Government final consumption expenditure, deflator

IGAA: Government fixed capital formation, value

PIGAA: Government fixed capital formation, deflator

SSPG: Social security benefits paid by the general government, value

SSRG: Social security contribution received by the general government, value

TIND: Taxes on production and imports, value

TOCR: Other current receipts, general government, value

TY: Total direct taxes, value

YPEPG: Property income paid by the government, value

YPERG: Property income received by the government, value

YPOTG: Other current outlays, general government, value.

The fiscal and economic variables of interest, expressed in real terms, are computed as follows:

$\mathrm{GDP}=(\mathrm{GDP}$, value $) / \mathrm{PGDP}$

Government purchases $=$ CGAA $/$ PCG + IGAA $/$ PIGAA

Tax revenues $=($ TIND + TY + SSRG + YPERG + TOCR $) /$ PGDP 
Transfers $=(\mathrm{SSPG}+\mathrm{YPEPG}+\mathrm{YPOTG}) / \mathrm{PGDP}$

Net taxes $=$ Tax revenues - Transfers

Government purchases, value $=$ CGAA + IGAA

Transfers, value $=$ SSPG + YPEPG + YPOTG

Public spending $=($ Government purchases, value + Transfers, value $) /$ PGDP

The OECD Social Expenditure database

The age-related public spending cannot be easily obtained from the System of National Accounts (SNA). As indicated by Adema et al. (2011), "the aggregate nature of the data included in social transfers (cash and in kind) in the SNA proved inadequate for an analysis of public social policy programs and trends." Therefore, the OECD implemented the OECD Social Expenditure database (SOCX), which provides comparable data on the aggregated public and private social expenditures for the OECD countries.

SOCX data are based on the following OECD definition of what is a social expenditure: "Social expenditure is the provision by public (and private) institutions of benefits to, and financial contributions targeted at, households and individuals in order to provide support during circumstances which adversely affect their welfare, provided that the provision of the benefits and financial contributions constitutes neither a direct payment for a particular good or service nor an individual contract or transfer." Thus, SOCX data allow cross-country comparisons of social expenditures. This database groups expenditures with a social purpose in nine policy areas: old age, survivors, incapacity-related benefits, health, family, active labor market program, unemployment, housing, and other social policy areas (see Adema et al., 2011 for details).

In our paper, we consider public social expenditures (i.e., social spending controlled by general government) of all types of expenditure (i.e., cash and in-kind social spending), measured in percentage of GDP. More precisely, we use from OECD (2018a) the following series:

SSP1 = Old-age (pensions, early retirement pensions, home-help and residential services for the elderly) public social spending in percentage of GDP. 
SSP5 = Family (child allowances and credits, childcare support, income support during leave and sole parent payments) public social spending in percentage of GDP SSP6 = Active labor market policies (employment services, training, employment incentives, integration of the disabled, direct job creation, and start-up incentives) public social spending in percentage of GDP

SSP7 = Unemployment (unemployment compensation, early retirement for labor market reasons) public social spending in percentage of GDP

The social public spending variables of interest, expressed in real terms, are computed as follows:

Old age spending $=$ SSP1/100*Real GDP

Family spending $=$ SSP $5 / 100 *$ Real GDP

Active labor programs spending $=$ SSP6/100*Real GDP

Unemployment spending $=$ SSP $7 / 100^{*}$ Real GDP

Annual series from detailed SOCX data are available for 1980-2013 ${ }^{18}$, except for Austria and Iceland; the data start in 1990. For Norway, the data start in 1988. Data on unemployment spending are not included in the SOCX database for Denmark ${ }^{19}$.

All variables of interest are expressed in per capita terms by using the average population data from Eurostat for the European countries and from OECD (2017) for OECD non-European countries, except when otherwise specified.

The mean values presented in Table A-1 complement those presented in section 3.1.1 and Table 1. To allow cross-country comparisons, we express fiscal variables in per capita constant 2010 USD terms ${ }^{20}$.

\footnotetext{
${ }^{18}$ For more details, see SOCX sources and methods (http://www.oecd.org/els/soc/ Annex-Description-Projections-S0CX2016.pdf).

${ }^{19}$ For more details, see SOCX Denmark country note (http://stats.oecd.org/wbos/fileview2. aspx?IDFile=5b564891-03a9-4987-b5d1-00cc17e2fdca).

${ }^{20}$ To do so, we use GDP per capita in US dollars, at constant prices, constant purchasing power parities, OECD base year 2010 from OECD (2018b).
} 
Table A-1: Summary statistics of other variables, averages per country over the sample period (1980-2015)

\begin{tabular}{|c|c|c|c|c|c|c|c|}
\hline Country & $\begin{array}{c}\text { Share of working } \\
\text { age pop. } \\
\text { (in \%) }\end{array}$ & $\begin{array}{l}\text { Employ. } \\
\text { rate } \\
(\text { in } \%)\end{array}$ & $\begin{array}{l}\text { Unemp. } \\
\text { rate } \\
(\text { in } \%)\end{array}$ & $\begin{array}{c}\text { Family Spend. } \\
\text { per capita } \\
(\mathrm{PPP}, 2010 \mathrm{USD})\end{array}$ & $\begin{array}{c}\text { Old age Spend. } \\
\text { per capita } \\
(\mathrm{PPP}, 2010 \mathrm{USD})\end{array}$ & $\begin{array}{c}\text { Active labor } \\
\text { Spend. per capita } \\
(\mathrm{PPP}, 2010 \text { USD })\end{array}$ & $\begin{array}{c}\text { Unemp. Spend. } \\
\text { per capita } \\
(\mathrm{PPP}, 2010 \mathrm{USD})\end{array}$ \\
\hline Austria & 67.26 & 67.63 & 4.15 & 1140 & 4380 & 472 & 437 \\
\hline Belgium & 66.14 & 60.36 & 8.42 & 1017 & 2859 & 683 & 1248 \\
\hline Denmark & 66.28 & 75.43 & 6.21 & 1946 & 4739 & 1718 & $\mathrm{~N} / \mathrm{A}$ \\
\hline Finland & 66.78 & 68.53 & 8.66 & 1274 & 3439 & 824 & 912 \\
\hline France & 65.04 & 62.14 & 8.80 & 1066 & 4042 & 744 & 599 \\
\hline Germany & 67.99 & 66.66 & 6.99 & 786 & 3127 & 816 & 550 \\
\hline Iceland & 65.05 & 81.98 & 3.35 & 1072 & 1164 & 50 & 224 \\
\hline Ireland & 64.40 & 59.80 & 10.85 & 1104 & 1419 & 707 & 707 \\
\hline Italy & 66.97 & 56.82 & 9.06 & 380 & 3952 & 311 & 277 \\
\hline Netherlands & 67.67 & 66.74 & 6.70 & 655 & 2408 & 1075 & 754 \\
\hline Norway & 64.96 & 75.82 & 3.59 & 2465 & 5410 & 1180 & 495 \\
\hline Portugal & 66.07 & 68.69 & 7.85 & 215 & 1586 & 233 & 196 \\
\hline Spain & 67.06 & 53.44 & 15.47 & 262 & 2071 & 370 & 723 \\
\hline Sweden & 64.42 & 76.76 & 6.50 & 1546 & 4079 & 1390 & 537 \\
\hline United Kingdom & 65.29 & 70.10 & 7.74 & 1024 & 1992 & 232 & 167 \\
\hline 15 European countries & 66.10 & 67.40 & 7.63 & 1064 & 3112 & 721 & 523 \\
\hline Australia & 67.15 & 68.99 & 6.95 & 1341 & 2281 & 381 & 435 \\
\hline Canada & 68.73 & 69.06 & 8.43 & 440 & 1691 & 336 & 412 \\
\hline Japan & 66.97 & 74.47 & 3.53 & 324 & 3148 & 210 & 167 \\
\hline United States & 66.56 & 69.72 & 6.43 & 303 & 2338 & 131 & 197 \\
\hline 19 OCDE countries & 66.36 & 68.06 & 7.36 & 967 & 2954 & 625 & 477 \\
\hline
\end{tabular}

Note : Sample period is 1980-2015 except for public social spending variables due to the lack of detailed SOCX data. For family, old age, active labor programs and unemployment spending, the sample period is 1990-2013. Source: Authors' computations based on data from Eurostat and, OECD (2016), OECD (2017) OECD (2018a) and OECD (2018b) databases. 


\section{A-2 Replication of the Literature on Fiscal Studies}

Here, we aim at establishing the suitability of our baseline estimated model by analyzing the responses of OECD economies to an increase in government purchases and by comparing them with those found in the fiscal policy literature. We computed the impulse responses to an increase in government purchases representing $1 \%$ of GDP. Table A-2 reports the coefficients for some periods after the shock. For per capita, GDP, government purchases and net taxes, the responses are expressed in percentage change, whereas for fiscal balance, the responses are in percentage points of GDP change. In response to its own shock, government purchases shock strongly increases by 4.23 percent on impact (which is the peak) and fades out gradually. The government purchase shock leads to a significant increase in GDP per capita by 2.79 percent on impact (the peak), remaining significant during four years after the shock. Net taxes per capita rise significantly until the sixth year after the shock, by 3.10 on impact and 3.15 one year after the shock (the peak). Consequently, government purchases increase causes a fiscal deficit that is significant during two years after the shock and represents -0.28 percentage points of GDP on impact (the peak).

Our evidence of the stimulating effect of an increase in government purchases in a SVAR that includes the net flow of migrants is consistent with the findings of previous studies (Blanchard and Perotti, 2002; Perotti, 2005; Beetsma et al., 2006, 2008 ; Beetsma and Guiliodori, 2011). Most notably, our spending multiplier is similar to estimates found by Beetsma and Guiliodori (2011), who use a panel VAR on 14 European countries (Austria, Belgium, Denmark, Finland, France, Ireland, Italy, Germany, Greece, the Netherlands, Portugal, Spain, Sweden, and the United Kingdom) over the period 19702004. They report a 1.18 percent increase in GDP per capita on impact, 1.52 percent after one year, 1.25 percent after three years in their specification including unadjusted net taxes (i.e., panel (d) of Table 4 p.F19). We present their results in Table A-2, panel (c) and compare them with a subset of our sample that includes the 15 European countries (Table A-2, panel (b)). Our estimates are quite similar to those of Beetsma and Guiliodori (2011) because we find a 2.38 percent increase in GDP per capita on impact, 
Table A-2: Responses to a government purchase increase of $1 \%$ of GDP

\begin{tabular}{|c|c|c|c|c|c|c|}
\hline \multicolumn{7}{|c|}{ (a) Baseline on 19 OECD countries, sample period 1980-2015 } \\
\hline & Year 0 & Year 1 & Year 2 & Year 3 & Year 5 & Year 10 \\
\hline Gov. purchases per capita & $4.23^{*}$ & $3.71^{*}$ & $2.99^{*}$ & $2.41^{*}$ & $1.60^{*}$ & $0.50^{*}$ \\
\hline Net taxes per capita & $3.10^{*}$ & $3.15^{*}$ & $2.79^{*}$ & $2.35^{*}$ & $1.47^{*}$ & 0.12 \\
\hline r capita & $2.79^{*}$ & $2.23^{*}$ & $1.69^{*}$ & $1.24^{*}$ & $0.64^{*}$ & -0.02 \\
\hline Fiscal balance/GDP & $-0.28^{*}$ & $-0.17^{*}$ & -0.10 & -0.06 & -0.07 & $-0.10^{*}$ \\
\hline \multicolumn{7}{|c|}{ (b) Baseline on 15 EU countries, sample period 1980-2015 } \\
\hline & Year 0 & Year 1 & Year 2 & Year 3 & Year 5 & Year 10 \\
\hline Gor & $4.14^{*}$ & $3.83^{*}$ & $3.01^{*}$ & $2.35^{*}$ & $1.49^{*}$ & 0.35 \\
\hline es per capita & $2.80^{*}$ & $3.03^{*}$ & $2.80^{*}$ & $2.40^{*}$ & $1.43^{*}$ & -0.12 \\
\hline GDP & $2.38^{*}$ & $2.07^{*}$ & $1.48^{*}$ & $1.01^{*}$ & 0.41 & -0.20 \\
\hline Fiscal balance/GDP & $-0.34^{*}$ & $-0.23^{*}$ & $-0.10^{*}$ & -0.05 & -0.05 & $-0.12^{*}$ \\
\hline \multicolumn{7}{|c|}{ (c) Beetsma and Guiliodori (2011) on 14 EU countries, sample period 1970-2004 } \\
\hline & Year 0 & Year 1 & Year 2 & Year 3 & Year 5 & Year 10 \\
\hline Gov & $4.15^{*}$ & $4.45^{*}$ & $\mathrm{~N} / \mathrm{A}$ & $3.26^{*}$ & $2.13^{*}$ & $\mathrm{~N} / \mathrm{A}$ \\
\hline Net & $1.16^{*}$ & $2.34^{*}$ & $\mathrm{~N} / \mathrm{A}$ & $1.83^{*}$ & 0.57 & $\mathrm{~N} / \mathrm{A}$ \\
\hline GDP per capita & $1.18^{*}$ & $1.52^{*}$ & $\mathrm{~N} / \mathrm{A}$ & $1.25^{*}$ & $0.73^{*}$ & $\mathrm{~N} / \mathrm{A}$ \\
\hline Fiscal balance/GDP & $-0.78^{*}$ & $-0.60^{*}$ & $\mathrm{~N} / \mathrm{A}$ & $-0.42^{*}$ & $-0.41^{*}$ & $\mathrm{~N} / \mathrm{A}$ \\
\hline
\end{tabular}

Notes: Year 0 stands for the year of the shock. ${ }^{*}$ denotes statistical significance at the $10 \%$ level. For per capita, GDP, government purchases and net taxes, the responses are expressed in percentage change; for fiscal balance/GDP, the responses are in percentage points change. Panel $(c)$ reports the impulses responses from Beetsma and Guiliodori (2011) p.F19, panel $(d)$ of Table 4.

2.07 percent after one year, 1.48 percent after two years and 1.01 percent after three years. We conclude that extending the SVAR model to international migration does not alter dynamic responses to fiscal shocks.

\section{A-3 Additional Specifications}

To discuss the demographic role of the migration shock in section 4 , we consider the following specifications in addition to the baseline specification presented in subsection 3.2.2:

$$
\begin{aligned}
Z_{i t}^{2} & =\left[m_{i t}, w a_{i t}, g_{i t}, n t_{i t}, y_{i t}\right]^{\prime} \\
Z_{i t}^{3} & =\left[m_{i t}, w a_{i t}, g_{i t}, n t_{i t}, \tilde{y}_{i t}\right]^{\prime} \\
Z_{i t}^{4} & =\left[m_{i t}, w a_{i t}, g_{i t}, n t_{i t}, p d t y_{i t}, e r_{i t}\right]^{\prime} \\
Z_{i t}^{5} & =\left[m_{i t}, g_{i t}, t r_{i t}, r e_{i t}, y_{i t}\right]^{\prime} \\
Z_{i t}^{6} & =\left[m_{i t}, p s_{i t}, r e_{i t}, y_{i t}\right]^{\prime}
\end{aligned}
$$




$$
\begin{aligned}
Z_{i t}^{7} & =\left[m_{i t}, p s_{i t}, f s_{i t}, r e_{i t}, y_{i t}\right]^{\prime} \\
Z_{i t}^{8} & =\left[m_{i t}, p s_{i t}, o a s_{i t}, r e_{i t}, y_{i t}\right]^{\prime} \\
Z_{i t}^{9} & =\left[m_{i t}, g_{i t}, n t_{i t}, y_{i t}, u_{i t}\right]^{\prime} \\
Z_{i t}^{10} & =\left[m_{i t}, p s_{i t}, r e_{i t}, y_{i t}, u_{i t}\right]^{\prime} \\
Z_{i t}^{11} & =\left[m_{i t}, p s_{i t}, a l s_{i t}, r e_{i t}, y_{i t}, u_{i t}\right]^{\prime} \\
Z_{i t}^{12} & =\left[m_{i t}, p s_{i t}, u s_{i t}, r e v_{i t}, y_{i t}, u_{i t}\right]^{\prime}
\end{aligned}
$$

where:

$m$ is the logarithm of $1+$ net migration as a share of the average population to handle negative values on net migration.

$g$, nt and $y$ are respectively the logarithms of per capita, government purchases, net taxes and GDP.

$\tilde{y}$ is the logarithm of the ratio of GDP to working-age population.

$r e$ and $t r$ are respectively the logarithms of per capita tax revenues and transfers.

$s p$ is the logarithm of per capita public spending.

oas, $f s$, las and us are respectively the logarithms of per capita; old age, family, active labor market programs and unemployment spending.

All economic and fiscal variables in this paper are expressed in real terms as indicated in Appendix A-1 Data.

$w a$, er and $u$ are the logarithms of the ratio of working-age to total population, the employment to working-age population and the unemployment rate.

The estimation sample is 1980-2015 for 19 OECD countries: Australia, Austria, Canada, Belgium, Denmark, Finland, France, Germany, Ireland, Iceland, Italy, Japan, the Netherlands, Norway, Spain, Sweden, Portugal, the United Kingdom and the United States. The only exceptions are the models including variables computed from detailed SOCX data due to shorter data availability. Specifically, the estimation sample covers the 19 OECD countries over the period 1990-2013 (to obtain the balanced panel required in our biased-corrected estimation ${ }^{21}$ ) for the following models: $Z_{i t}^{7}, Z_{i t}^{8}$ and $Z_{i t}^{11}$. Because Data on unemployment benefits are not available for Denmark in the SOCX database,

\footnotetext{
${ }^{21}$ See Hahn and Kuersteiner (2002) for more details.
} 
model $Z_{i t}^{12}$ is estimated for 18 OECD countries over the period 1990-2013.

Note that net flow of migrants is ordered first in the Choleski decomposition for the reasons presented and discussed in the paper for the baseline specification. We place the ratio of working-age to total population after the migration rate in models $Z_{i t}^{2}, Z_{i t}^{3}$ and $Z_{i t}^{4}$. Since migrants are mainly of working age, migration shock contemporaneously affects the working-age population. We did recalculate our impulse response functions for the alternative ordering and found the results unchanged.

Consider that since immigration is ordered first, the order between the other variables does not matter for the analysis of the effect of a migration shock. Nevertheless, we follow the standard practices in the literature on the effect of the fiscal policy to order the economic and fiscal variables. Thus, we place the unemployment rate after GDP per capita in the system as in d'Albis et al. (2018). This ordering is justified by the fact that labor productivity shocks can contemporaneously affect the unemployment rate. For the same reason, we place the employment rate after GDP per employee in model $Z_{i t}^{4}$. In model $Z_{i t}^{5}$, we placed transfers before revenues in the Choleski decomposition, considering that there is no unique way to ordering these two variables. We also recalculated our impulse response functions for alternative ordering and found the results unchanged. In the models $Z_{i t}^{7}, Z_{i t}^{8}, Z_{i t}^{11}$ and $Z_{i t}^{12}$, we placed public spending $s p$ before social public spending variables in the Choleski decomposition. Our results are unchanged for an alternative ordering. 


\section{Appendix B Supplementary Results}

\section{B-1 Tables of the Baseline Model}

Table B-1: Responses to migration shock

\begin{tabular}{lccccc}
\hline \hline & Year 0 & Year 1 & Year 2 & Year 5 & Year 10 \\
\hline Net flow of migrants & $1.00^{*}$ & $0.94^{*}$ & $0.63^{*}$ & 0.08 & 0.00 \\
Gov. purchases per capita & $0.22^{*}$ & $0.44^{*}$ & $0.47^{*}$ & $0.26^{*}$ & 0.03 \\
Net taxes per capita & $0.85^{*}$ & $1.11^{*}$ & $0.90^{*}$ & 0.14 & -0.09 \\
GDP per capita & $0.25^{*}$ & $0.31^{*}$ & $0.26^{*}$ & 0.03 & -0.06 \\
Fiscal balance/GDP & $0.12^{*}$ & $0.12^{*}$ & $0.07^{*}$ & -0.03 & $-0.03^{*}$ \\
\hline
\end{tabular}

Notes: Year 0 stands for the year of the shock. ${ }^{*}$ denotes statistical significance at the $10 \%$ level. The size of the migration shock is set to 1 incoming individual per thousand inhabitants. For net flow of migrants, the responses are expressed in per 1000 points change. For per capita variables, the responses are expressed in percentage change. For fiscal balance to GDP ratio, the responses are in percentage points change.

Table B-2: Percentage of the fluctuations attributable to migration shock

\begin{tabular}{lccccc}
\hline \hline & Year 0 & Year 1 & Year 2 & Year 5 & Year 10 \\
\hline Net flow of migrants & 100.00 & 98.65 & 96.26 & 89.30 & 86.69 \\
Gov. purchases per capita & 1.43 & 3.99 & 5.76 & 6.86 & 6.27 \\
Net taxes per capita & 6.43 & 8.41 & 8.59 & 7.20 & 6.58 \\
GDP per capita & 2.10 & 3.31 & 3.62 & 3.06 & 2.84 \\
\hline
\end{tabular}

Notes: Year 0 stands for the year of the shock. The percentage of fluctuations attributable to migration shock is the forecast error variance of the corresponding variable explained by migration shock. 


\section{B-2 Robustness Analysis}

\section{Sample Heterogeneity}

Table B-3: Responses to migration shock, sample heterogeneity

\begin{tabular}{lccccc}
\hline \hline \multicolumn{5}{c}{ (a) Excluding non-European countries } \\
Excluding Australia, Canada, Japan and & USA \\
\cline { 2 - 6 } & Year 0 & Year 1 & Year 2 & Year 5 & Year 10 \\
\hline Net flow of migrants & $1.00^{*}$ & $0.90^{*}$ & $0.56^{*}$ & 0.03 & -0.02 \\
Gov. purchases per capita & $0.24^{*}$ & $0.44^{*}$ & $0.47^{*}$ & 0.18 & -0.02 \\
Net taxes per capita & $0.91^{*}$ & $1.12^{*}$ & $0.77^{*}$ & -0.04 & -0.12 \\
GDP per capita & $0.27^{*}$ & $0.32^{*}$ & $0.26^{*}$ & -0.01 & -0.07 \\
Fiscal balance/GDP & $0.14^{*}$ & $0.13^{*}$ & $0.05^{*}$ & -0.05 & -0.02 \\
\hline \hline
\end{tabular}

(b) Excluding the 4 countries with the highest migration rate Excluding Australia, Canada, Spain and Germany

\begin{tabular}{lccccc} 
& Year 0 & Year 1 & Year 2 & Year 5 & Year 10 \\
\hline Net flow of migrants & $1.00^{*}$ & $0.87^{*}$ & $0.47^{*}$ & 0.00 & -0.01 \\
Gov. purchases per capita & $0.32^{*}$ & $0.60^{*}$ & $0.59^{*}$ & 0.19 & -0.01 \\
Net taxes per capita & $0.82^{*}$ & $1.04^{*}$ & $0.71^{*}$ & -0.05 & -0.15 \\
GDP per capita & $0.33^{*}$ & $0.36^{*}$ & $0.28^{*}$ & -0.03 & -0.08 \\
Fiscal balance/GDP & $0.10^{*}$ & $0.07^{*}$ & 0.01 & -0.06 & $-0.03^{*}$ \\
\hline \hline
\end{tabular}

(c) Excluding the 4 countries with the lowest migration rate Excluding France, Ireland, Portugal and Japan

\begin{tabular}{lccccc} 
& Year 0 & Year 1 & Year 2 & Year 5 & Year 10 \\
\hline Net flow of migrants & $1.00^{*}$ & $0.88^{*}$ & $0.50^{*}$ & 0.00 & 0.00 \\
Gov. purchases per capita & 0.06 & 0.11 & $0.17^{*}$ & $0.16^{*}$ & 0.06 \\
Net taxes per capita & $0.68^{*}$ & $0.81^{*}$ & $0.61^{*}$ & 0.13 & 0.04 \\
GDP per capita & $0.15^{*}$ & 0.09 & 0.12 & 0.08 & 0.02 \\
Fiscal balance/GDP & $0.13^{*}$ & $0.14^{*}$ & $0.09^{*}$ & -0.01 & 0.00 \\
\hline \hline
\end{tabular}

(d) Excluding the 4 countries with the highest fiscal balance Excluding Belgium, Italy, Portugal and USA

\begin{tabular}{lccccc}
\cline { 2 - 6 } & Year 0 & Year 1 & Year 2 & Year 5 & Year 10 \\
\hline Net flow of migrants & $1.00^{*}$ & $0.94^{*}$ & $0.69^{*}$ & $0.21^{*}$ & 0.02 \\
Gov. purchases per capita & $0.29^{*}$ & $0.56^{*}$ & $0.57^{*}$ & $0.35^{*}$ & 0.05 \\
Net taxes per capita & $0.83^{*}$ & $1.21^{*}$ & $1.10^{*}$ & 0.35 & -0.10 \\
GDP per capita & $0.28^{*}$ & $0.39^{*}$ & $0.31^{*}$ & 0.05 & -0.08 \\
Fiscal balance/GDP & $0.10^{*}$ & $0.11^{*}$ & $0.08^{*}$ & -0.02 & $-0.04^{*}$ \\
\hline \hline
\end{tabular}

Notes: Year 0 stands for the year of the shock. * denotes statistical significance at the $10 \%$ level.The size of the migration shock is set to 1 incoming individual per thousand inhabitants. For net flow of migrants, the responses are expressed in per 1000 points change. For per capita variables, the responses are expressed in percentage change. For fiscal balance to GDP ratio, the responses are in percentage points change. 
Table B-3: Responses to migration shock, sample heterogeneity (continued)

(e) Excluding the 4 countries with the lowest fiscal balance Excluding Norway, Iceland, Finland and Germany

\begin{tabular}{lccccc} 
& Year 0 & Year 1 & Year 2 & Year 5 & Year 10 \\
\hline Net flow of migrants & $1.00^{*}$ & $1.02^{*}$ & $0.73^{*}$ & 0.07 & -0.03 \\
Gov. purchases per capita & $0.19^{*}$ & $0.45^{*}$ & $0.52^{*}$ & $0.25^{*}$ & -0.05 \\
Net taxes per capita & $0.98^{*}$ & $1.35^{*}$ & $1.06^{*}$ & -0.07 & $-0.24^{*}$ \\
GDP per capita & $0.27^{*}$ & $0.39^{*}$ & $0.32^{*}$ & -0.05 & $-0.14^{*}$ \\
Fiscal balance/GDP & $0.17^{*}$ & $0.18^{*}$ & $0.11^{*}$ & $-0.08^{*}$ & $-0.04^{*}$ \\
\hline \hline
\end{tabular}

(f) Excluding the 4 countries with the highest share of skilled migrants Excluding Australia, Canada, Ireland and UK

\begin{tabular}{lccccc}
\cline { 2 - 5 } & Year 0 & Year 1 & Year 2 & Year 5 & Year 10 \\
\hline Net flow of migrants & $1.00^{*}$ & $0.89^{*}$ & $0.54^{*}$ & 0.05 & 0.01 \\
Gov. purchases per capita & $0.11^{*}$ & $0.19^{*}$ & $0.24^{*}$ & $0.22^{*}$ & $0.10^{*}$ \\
Net taxes per capita & $0.74^{*}$ & $0.89^{*}$ & $0.73^{*}$ & 0.32 & 0.08 \\
GDP per capita & $0.19^{*}$ & $0.14^{*}$ & $0.17^{*}$ & 0.12 & 0.02 \\
Fiscal balance/GDP & $0.13^{*}$ & $0.14^{*}$ & $0.09^{*}$ & 0.02 & -0.01 \\
\hline \hline
\end{tabular}

(g) Excluding the 4 countries with the lowest share of skilled migrants Excluding Austria, Italy, Portugal and Germany

\begin{tabular}{lccccc} 
& Year 0 & Year 1 & Year 2 & Year 5 & Year 10 \\
\hline Net flow of migrants & $1.00^{*}$ & $1.03^{*}$ & $0.73^{*}$ & 0.06 & -0.02 \\
Gov. purchases per capita & $0.29^{*}$ & $0.65^{*}$ & $0.70^{*}$ & $0.31^{*}$ & -0.01 \\
Net taxes per capita & $1.05^{*}$ & $1.53^{*}$ & $1.28^{*}$ & 0.04 & -0.23 \\
GDP per capita & $0.37^{*}$ & $0.51^{*}$ & $0.41^{*}$ & -0.04 & $-0.13^{*}$ \\
Fiscal balance/GDP & $0.16^{*}$ & $0.17^{*}$ & $0.11^{*}$ & -0.07 & $-0.05^{*}$ \\
\hline
\end{tabular}

Notes: Year 0 stands for the year of the shock. * denotes statistical significance at the $10 \%$ level.The size of the migration shock is set to 1 incoming individual per thousand inhabitants. For net flow of migrants, the responses are expressed in per 1000 points change. For per capita variables, the responses are expressed in percentage change. For fiscal balance to GDP ratio, the responses are in percentage points change. 
Table B-4: Percentage of the fluctuations attributable to migration shock, sample heterogeneity

\begin{tabular}{lccccc}
\hline \hline \multicolumn{5}{c}{ (a) Excluding non-European countries } \\
Excluding Australia, Canada, Japan and & USA & \\
\cline { 2 - 6 } & Year 0 & Year 1 & Year 2 & Year 5 & Year 10 \\
\hline Net flow of migrants & 100.00 & 97.18 & 92.46 & 80.72 & 76.99 \\
Gov. purchases per capita & 2.20 & 4.96 & 6.73 & 6.92 & 6.01 \\
Net taxes per capita & 9.24 & 10.87 & 9.92 & 7.35 & 6.84 \\
GDP per capita & 3.39 & 4.63 & 4.80 & 3.75 & 3.65 \\
\hline \hline
\end{tabular}

(b) Excluding the 4 countries with the highest migration rate Excluding Australia, Canada, Spain and Germany

\begin{tabular}{lccccc} 
& Year 0 & Year 1 & Year 2 & Year 5 & Year 10 \\
\hline Net flow of migrants & 100.00 & 96.77 & 92.75 & 83.35 & 80.04 \\
Gov. purchases per capita & 3.16 & 7.32 & 9.38 & 8.90 & 7.82 \\
Net taxes per capita & 5.85 & 7.15 & 6.61 & 5.00 & 4.68 \\
GDP per capita & 3.95 & 5.03 & 4.99 & 3.78 & 3.66 \\
\hline \hline
\end{tabular}

(c) Excluding the 4 countries with the lowest migration rate Excluding France, Ireland, Portugal and Japan

\begin{tabular}{|c|c|c|c|c|c|}
\hline & Year 0 & Year 1 & Year 2 & Year 5 & Year 10 \\
\hline Net flow of migrants & 100.00 & 99.07 & 97.13 & 93.07 & 92.66 \\
\hline Gov. purchases per ca & 0.23 & 0.48 & 1.03 & 2.38 & 2.77 \\
\hline Net taxes per capita & 5.10 & 6.11 & 6.16 & 5.58 & 5.36 \\
\hline GDP per capita & 0.93 & 0.85 & 1.00 & 1.28 & 1.33 \\
\hline \multicolumn{6}{|c|}{$\begin{array}{l}\text { (d) Excluding the } 4 \text { countries with the highest fiscal balance } \\
\text { Excluding Belgium, Italy, Portugal and USA }\end{array}$} \\
\hline & Year 0 & Year 1 & Year 2 & Year 5 & Year 10 \\
\hline Net $\mathrm{fl}$ & 100.00 & 98.11 & 96.09 & 89.83 & 86.38 \\
\hline Gov. purchas & 1.69 & 4.53 & 6.20 & 7.35 & 6.85 \\
\hline Net & 4.73 & 7.33 & 8.32 & 7.98 & 7.34 \\
\hline GDP per capita & 1.83 & 3.37 & 3.68 & 3.17 & 2.99 \\
\hline
\end{tabular}

Notes: Year 0 stands for the year of the shock. The percentage of fluctuations attributable to migration shock is the forecast error variance of the corresponding variable explained by migration shock. 
Table B-4: Percentage of the fluctuations attributable to migration shock, sample heterogeneity (continued)

\begin{tabular}{|c|c|c|c|c|c|}
\hline \multicolumn{6}{|c|}{$\begin{array}{l}\text { (e) Excluding the } 4 \text { countries with the lowest fiscal balance } \\
\text { Excluding Norway, Iceland, Finland and Germany }\end{array}$} \\
\hline & Year 0 & Year 1 & Year 2 & Year 5 & Year 10 \\
\hline Net flow of $\mathrm{m}$ & 100.00 & 99.40 & 97.52 & 89.86 & 86 \\
\hline Gov. purchas & & 80 & & 7.43 & \\
\hline Net taxes per capita & 10.15 & 13.39 & 13 & 9.76 & 9.19 \\
\hline GDP per capita & & 4.09 & & 3.53 & 3.83 \\
\hline \multicolumn{6}{|c|}{$\begin{array}{l}\text { (f) Excluding the } 4 \text { countries with the highest share of skilled migrants } \\
\text { Excluding Australia, Canada, Ireland and UK }\end{array}$} \\
\hline & Year 0 & Year 1 & Year 2 & Year 5 & Year 10 \\
\hline Net flow & 100.00 & 98.28 & & 89.97 & \\
\hline Gov. pur & 1.12 & 1.85 & & 4.60 & 5. \\
\hline Net taxe & 5.36 & 6.28 & 6.49 & 6.56 & 6.53 \\
\hline GDP per capita & 2.50 & 2.36 & 2.73 & 3.57 & 3.68 \\
\hline \multicolumn{6}{|c|}{$\begin{array}{c}\text { (g) Excluding the } 4 \text { countries with the lowest share of skilled migrants } \\
\text { Excluding Austria, Italy, Portugal and Germany }\end{array}$} \\
\hline & Year 0 & Year 1 & Year 2 & Year 5 & Year 10 \\
\hline Net flow of $\mathrm{mi}$ & 100.00 & 99.37 & 98.20 & 92.85 & 90.71 \\
\hline Gov. purchases per & 1.91 & 6.42 & 9 . & 10.82 & 9.54 \\
\hline Net taxes per & 9.03 & 12.96 & 13.54 & 10.96 & 10.22 \\
\hline GDP per capita & 3.33 & 6.05 & 6.59 & 5.20 & 5.18 \\
\hline
\end{tabular}

Notes: Year 0 stands for the year of the shock. The percentage of fluctuations attributable to migration shock is the forecast error variance of the corresponding variable explained by migration shock. 


\section{Anticipation Issue}

As noted by Blanchard and Perotti (2002), the identification of a fiscal shock in VAR models must address two different sources of lag: a decision lag, which is the interval of time between the shock and the policy response, and an implementation lag, which is due to time needed to implement a political decision.

The decision lag is helpful for the identification because it justifies the idea that fiscal policy does not respond contemporaneously to economic shocks. Conversely, the implementation lag makes the identification of the fiscal structural shock trickier because it causes a so-called foresight or anticipation effect; due to the implementation lag, private agents might anticipate the fiscal policy change, which could lead to change in microeconomic behaviors and ultimately to macroeconomic changes ${ }^{22}$.

When identifying a migration shock, we are subject to two analogous sources of lags. On the one hand, the decision to migrate is generally made before immigration, and is made according to the current economic conditions and migration policy that are observed in the host country. We use this argument in our recursive (Choleski) identification scheme. Nevertheless, we cannot exclude the idea that the migration decision might be based on migrants' expectations. This possibility is considered in the VAR analysis (due to its intrinsic dynamic structure), because the most relevant variable (GDP) considered in these expectations is included in the VAR ( Stock and Watson, 2001) ${ }^{23}$. On the other hand, we can imagine that private agents in the host country also develop expectations concerning future immigration inflows and react to them, which might cause an anticipation effect similar to those induced by an implementation lag.

In this subsection, we aim at showing that the anticipation problem is inconsequential with respect identification of a migration shock. This is due to the predominance of unanticipated causes of international migration (such as geopolitical factors or natural disasters) and the difficulty in predicting a migration policy (Massey and Pren, 2012). To test whether the anticipation problem is inconsequential in our analysis, we follow the

\footnotetext{
22 See Leeper et al. (2013) for the consequences of the anticipation effect and the existing empirical methods to handle foresight in the VAR analysis of fiscal shocks.

${ }^{23}$ For example, since Sims (1992), to account for the fact that the monetary authority sets interest rates depending on expected inflation, the practice is to include commodity prices in the VAR system.
} 
literature (e.g., Yang, 2007 and Beetsma and Guiliodori, 2011) by including "forwardlooking" variables in the VAR, which are intended to contain information about the future effects of shocks. We thus extend our baseline model with two important forward-looking variables, namely the logarithm of the GDP deflator and the short term nominal interest rate. Following the literature, they are placed last in the Choleski ordering. The results reported in Figure B-1 and Table B-5 reveal impulse responses that are roughly the same as the estimation of our baseline model reported in Figure 2 and Table B-1. Our results are robust and the anticipation issue does not appear relevant for our analysis, suggesting that migration shocks are largely unanticipated or difficult to anticipate.

Table B-5: Responses to migration shock, anticipation issue

\begin{tabular}{lccccc}
\hline \hline & Year 0 & Year 1 & Year 2 & Year 5 & Year 10 \\
\hline Net flow of migrants & $1.00^{*}$ & $0.94^{*}$ & $0.69^{*}$ & $0.19^{*}$ & 0.02 \\
Gov. purchases per capita & $0.16^{*}$ & $0.37^{*}$ & $0.39^{*}$ & 0.24 & 0.02 \\
Net taxes per capita & $0.67^{*}$ & $0.91^{*}$ & $0.82^{*}$ & 0.22 & -0.05 \\
GDP per capita & $0.20^{*}$ & $0.29^{*}$ & $0.24^{*}$ & 0.03 & -0.05 \\
Fiscal balance/GDP & $0.10^{*}$ & $0.10^{*}$ & $0.07^{*}$ & -0.01 & -0.02 \\
\hline \hline
\end{tabular}

Notes: Year 0 stands for the year of the shock. ${ }^{*}$ denotes statistical significance at the $10 \%$ level. The size of the migration shock is set to 1 incoming individual per thousand inhabitants. For per capita variables, the responses are in percentage change. For the fiscal balance to GDP ratio, the response is in percentage points change. 
Figure B-1: Responses to migration shock, anticipation issue
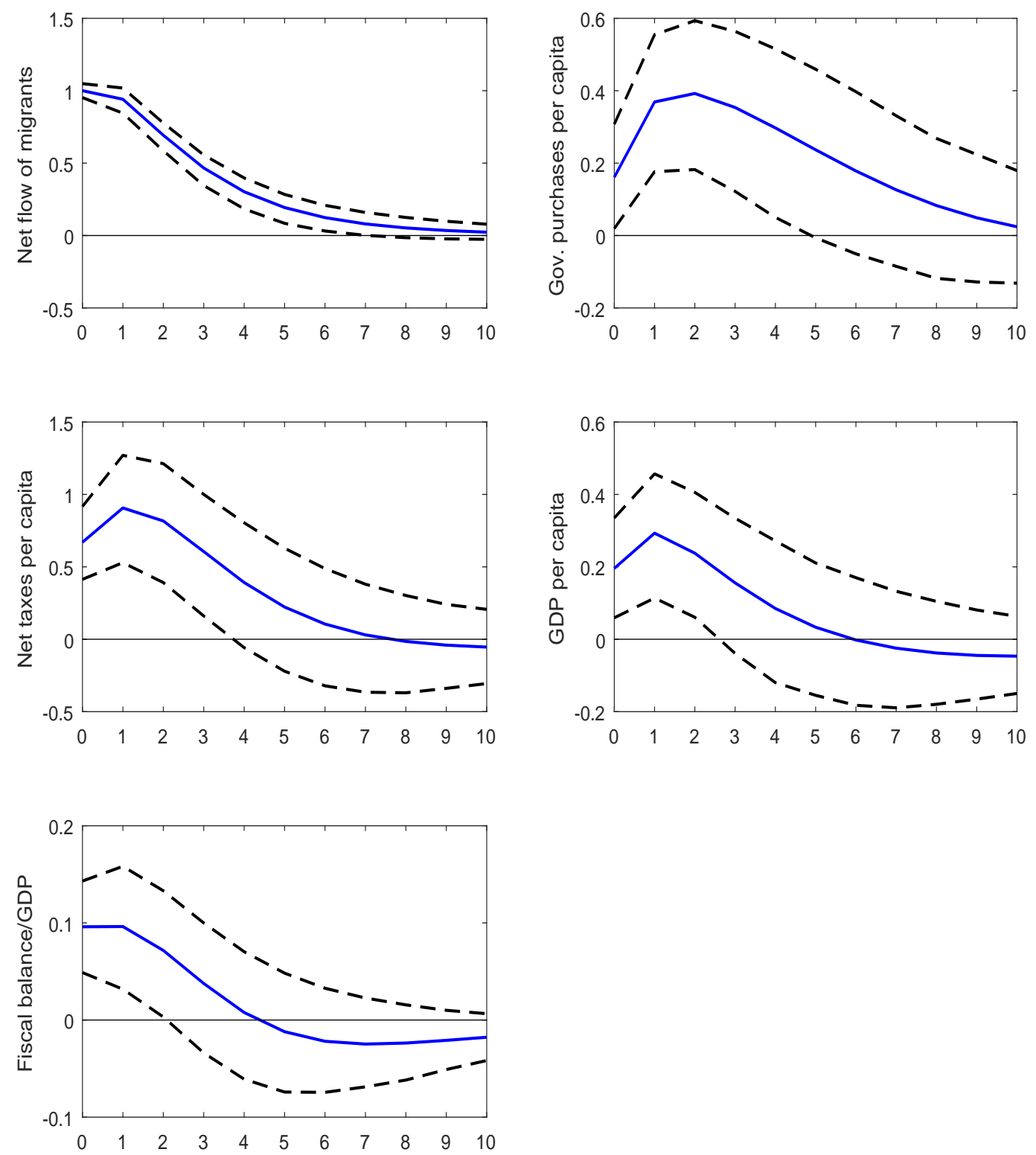

Notes: The solid line gives the estimated impulse responses. Dashed lines give the $90 \%$ confidence intervals generated by Monte Carlo with 5000 repetitions. The responses of net flow of migrants are in per 1000 points change. For per capita variables, the responses are in percentage change. For the fiscal balance to GDP ratio, the response is in percentage points change. 


\section{Identification using Sign Restrictions}

Let us now use as robustness checks of our results an alternative identification that is not recursive and employs sign restrictions (see Fry and Pagan (2011) for a review of the estimation of SVAR with sign restrictions). This approach was recently used by Furlanetto and Robstad (2016) to analyze the macroeconomic effects of immigration in Norway.

In the absence of a strong theoretical basis, it is difficult to choose the appropriate sign restrictions on macroeconomic variables to identify migration shocks. Considering that limitation, we use this method as a robustness check of our main empirical results as we did in d'Albis et al. (2016). In that respect, we consider an identification scheme based on sign restrictions with a penalty function criterion proposed by Faust (1998) and Uhlig (2005) to identify monetary policy shocks.

Conceptually, the identification scheme based on sign restrictions with a penalty function criterion is as follow. Rather than having to identify matrix $B_{0}^{-1}$, this approach consists of identifying a vector column $b$ of $B_{0}^{-1}$, the structural responses of the VAR model variables to a particular shock, which minimizes the following criterion function

$$
\Psi(b)=\sum_{k} \sum_{h=0}^{H} \psi\left(\iota_{k} \frac{\theta_{k, h}(b)}{\sigma_{k}}\right)
$$

where $\psi$ is the function $\psi(x)=x$ if $x \leq 0$ and $\psi(x)=100 \times x$ if $x>0, \theta_{k, h}(b)$ is the impulse response of the variable $k$ to the impulse vector $b$ at horizon $h, \sigma_{k}$ is the standard error of variable $k, \iota_{k}=-1$ if the impulse response of the variable $k$ is restricted to be positive and $\iota_{k}=1$ otherwise. ${ }^{24}$

We identify the migration shock using the penalty function criterion so that it increases the net migration rate and the ratio of working-age population to total population for the first two years after the shock. The restriction on the response of the share of workingage population, consistent with the assumption in the theoretical model, is justified by the structure of international migration that primarily consists of working age people.

\footnotetext{
${ }^{24}$ We implement this minimization using the Matlab fmincon algorithm.
} 
Ignoring this restriction does not qualitatively alter our finding.

To conduct the identification schemes using sign restrictions, the baseline specification is extended to include the logarithm of the ratio of working-age population to total population. The impulse responses to migration shock are reported in Figure B-2 and Table B-6. As in Uhlig (2005), confidence bands are computed using a Bayesian approach by taking many draws from the posterior of the VAR coefficients and the variance-covariance matrix $\Omega$. For each draw the shocks are identified using the criteria described above. We consider the $68 \%$ confidence interval that is preferred in this approach.

The impulse responses in Figure B-2 and Table B-6 clearly support the evidence that international migration increases the economic and fiscal performances of OECD countries. The results are qualitatively similar to those obtained using a recursive identification scheme in Figure 2 and Table B-1. Those dynamics, which are consistent with our theoretical findings, support our main empirical results based on a recursive identification scheme.

Table B-6: Responses to migration shock, identification using sign restrictions

\begin{tabular}{lccccc}
\hline \hline & Year 0 & Year 1 & Year 2 & Year 5 & Year 10 \\
\hline Net flow of migrants & $1.00^{*}$ & $0.94^{*}$ & $0.63^{*}$ & $0.09^{*}$ & 0.00 \\
Working-age pop./Total pop. & $0.09^{*}$ & $0.08^{*}$ & $0.07^{*}$ & $0.02^{*}$ & 0.00 \\
Gov. purchases per capita & $0.25^{*}$ & $0.45^{*}$ & $0.48^{*}$ & $0.26^{*}$ & 0.04 \\
Net taxes per capita & $0.85^{*}$ & $1.10^{*}$ & $0.90^{*}$ & 0.16 & -0.08 \\
GDP per capita & $0.29^{*}$ & $0.32^{*}$ & $0.27^{*}$ & 0.04 & -0.05 \\
Fiscal balance/GDP & $0.12^{*}$ & $0.12^{*}$ & 0.07 & -0.03 & $-0.03^{*}$ \\
\hline \hline
\end{tabular}

Notes: Year 0 stands for the year of the shock. ${ }^{*}$ denotes statistical significance at the $32 \%$ level. The size of the migration shock is set to 1 incoming individual per thousand inhabitants. For per capita variables, the responses are expressed in percentage change; for the fiscal balance/GDP, the responses are in percentage points change. 
Figure B-2: Responses to migration shock, identification using sign restrictions
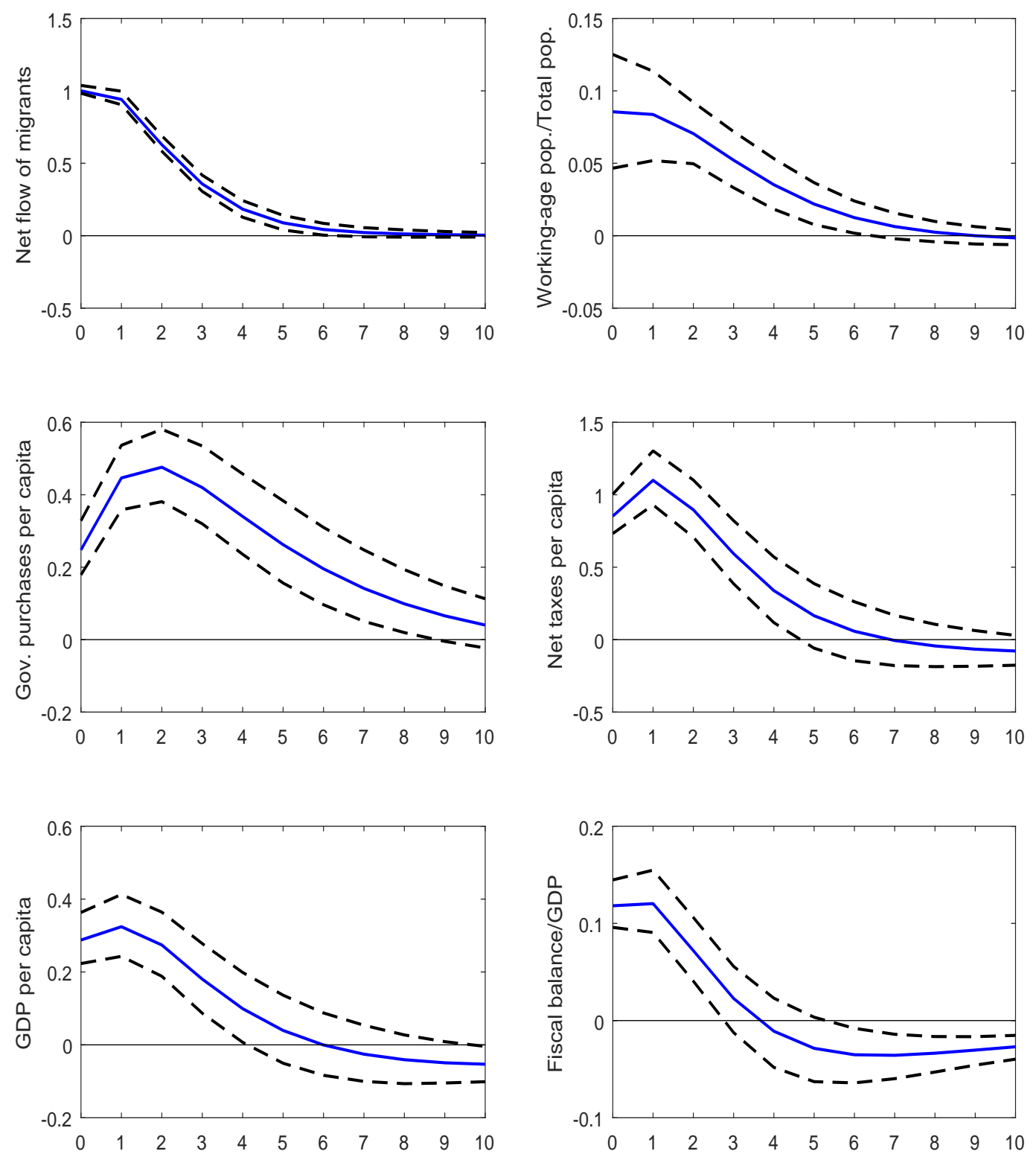

Notes: The solid line gives the estimated impulse responses. Dashed lines give the $68 \%$ confidence intervals computed by the Bayesian approach by tacking 5000 draws from the posterior of the VAR coefficients and the variance-covariance matrix of errors. 


\section{B-3 Tables of Additional Specifications}

Table B-7: Responses to migration shock, demographic benefit

\begin{tabular}{lccccc}
\hline \hline \multirow{5}{*}{ (a) Model 2 including the share } & of working-age population & \\
\cline { 2 - 6 } & Year 0 & Year 1 & Year 2 & Year 5 & Year 10 \\
\hline Net flow of migrants & $1.00^{*}$ & $0.94^{*}$ & $0.62^{*}$ & 0.08 & 0.00 \\
Working age pop. / Total pop & $0.04^{*}$ & $0.06^{*}$ & $0.06^{*}$ & 0.02 & 0.00 \\
Gov. purchases per capita & $0.21^{*}$ & $0.43^{*}$ & $0.46^{*}$ & $0.25^{*}$ & 0.03 \\
Net taxes per capita & $0.83^{*}$ & $1.09^{*}$ & $0.88^{*}$ & 0.14 & -0.09 \\
GDP per capita & $0.25^{*}$ & $0.31^{*}$ & $0.26^{*}$ & 0.03 & -0.06 \\
Fiscal balance/GDP & $0.12^{*}$ & $0.12^{*}$ & $0.07^{*}$ & -0.03 & $-0.03^{*}$ \\
\hline \hline
\end{tabular}

(b) Model 3 with GDP per capita decomposition in 2 components: share of working-age pop. and GDP per working age pop.

\begin{tabular}{lccccc} 
& Year 0 & Year 1 & Year 2 & Year 5 & Year 10 \\
\hline Net flow of migrants & $1.00^{*}$ & $0.94^{*}$ & $0.62^{*}$ & 0.08 & 0.00 \\
Working age pop. / Total pop & $0.04^{*}$ & $0.06^{*}$ & $0.06^{*}$ & 0.02 & 0.00 \\
Gov. purchases per capita & $0.21^{*}$ & $0.43^{*}$ & $0.46^{*}$ & $0.25^{*}$ & 0.03 \\
Net taxes per capita & $0.83^{*}$ & $1.09^{*}$ & $0.88^{*}$ & 0.14 & -0.09 \\
GDP per working age pop. & $0.19^{*}$ & $0.21^{*}$ & $0.17^{*}$ & 0.00 & -0.05 \\
Fiscal balance/GDP & $0.12^{*}$ & $0.12^{*}$ & $0.07^{*}$ & -0.03 & $-0.03^{*}$ \\
\hline \hline
\end{tabular}

(c) Model 4 with GDP per capita decomposition in 3 components: share of working-age pop., labor productivity and employment rate

\begin{tabular}{lccccc} 
& Year 0 & Year 1 & Year 2 & Year 5 & Year 10 \\
\hline Net flow of migrants & $1.00^{*}$ & $0.94^{*}$ & $0.61^{*}$ & 0.09 & 0.01 \\
Working age pop./Total pop & $0.04^{*}$ & $0.06^{*}$ & $0.06^{*}$ & 0.02 & 0.00 \\
Gov. purchases per capita & $0.22^{*}$ & $0.45^{*}$ & $0.49^{*}$ & 0.27 & 0.03 \\
Net taxes per capita & $0.83^{*}$ & $1.12^{*}$ & $0.94^{*}$ & 0.23 & -0.14 \\
Productivity & 0.06 & 0.04 & -0.03 & $-0.15^{*}$ & $-0.10^{*}$ \\
Employment/working age pop. & $0.11^{*}$ & $0.14^{*}$ & $0.18^{*}$ & $0.12^{*}$ & 0.01 \\
Fiscal balance/GDP & $0.11^{*}$ & $0.11^{*}$ & $0.06^{*}$ & -0.03 & $-0.04^{*}$ \\
\hline \hline
\end{tabular}

Notes: Year 0 stands for the year of the shock. ${ }^{*}$ denotes statistical significance at the $10 \%$ level. The size of migration shock is set to 1 incoming individual per thousand inhabitants. For net flow of migrants, the responses are in per 1000 points change. For government purchases per capita, net taxes per capita and labor productivity the responses are expressed in percentage change. For working age to population ratio, employment rate and fiscal balance to GDP ratio, the responses are in percentage points change. 
Table B-8: Responses to migration shock, age structure of public spending

(a) Model 5 with gov. purchases, transfers and tax revenues

\begin{tabular}{lccccc} 
& Year 0 & Year 1 & Year 2 & Year 5 & Year 10 \\
\hline Gov. purchases per capita & $0.21^{*}$ & $0.43^{*}$ & $0.47^{*}$ & $0.25^{*}$ & 0.01 \\
Transfers per capita & $-0.23^{*}$ & $-0.20^{*}$ & -0.15 & -0.02 & 0.00 \\
Tax revenues per capita & $0.33^{*}$ & $0.48^{*}$ & $0.37^{*}$ & 0.03 & -0.05 \\
GDP per capita & $0.24^{*}$ & $0.30^{*}$ & $0.26^{*}$ & 0.02 & -0.07 \\
Gov. purchases/GDP & -0.01 & $0.03^{*}$ & $0.05^{*}$ & $0.05^{*}$ & 0.02 \\
Transfers/GDP & $-0.11^{*}$ & $-0.12^{*}$ & $-0.10^{*}$ & -0.01 & 0.02 \\
Tax revenues/GDP & $0.04^{*}$ & $0.08^{*}$ & $0.04^{*}$ & 0.00 & 0.01 \\
\hline \hline
\end{tabular}

\begin{tabular}{lccccc}
\hline \hline \multicolumn{5}{c}{ (b) Model 6 with public spending } & and tax revenues \\
\cline { 2 - 6 } & Year 0 & Year 1 & Year 2 & Year 5 & Year 10 \\
\hline Spending per capita & 0.04 & $0.21^{*}$ & $0.25^{*}$ & $0.16^{*}$ & 0.01 \\
Tax revenues per capita & $0.31^{*}$ & $0.46^{*}$ & $0.32^{*}$ & -0.01 & -0.04 \\
GDP per capita & $0.23^{*}$ & $0.28^{*}$ & $0.21^{*}$ & -0.03 & -0.07 \\
Spending/GDP & $-0.09^{*}$ & -0.04 & 0.02 & $0.09^{*}$ & $0.04^{*}$ \\
Tax revenues/GDP & $0.04^{*}$ & $0.08^{*}$ & $0.05^{*}$ & 0.01 & 0.00 \\
\hline \hline
\end{tabular}

\begin{tabular}{lccccc}
\hline \hline \multirow{2}{*}{ (c) Model 7 with public spend. and tax revenues, including family spend. } \\
\cline { 2 - 6 } & Year 0 & Year 1 & Year 2 & Year 5 & Year 10 \\
\hline Public spend. per capita & 0.04 & $0.17^{*}$ & $0.36^{*}$ & $0.27^{*}$ & -0.04 \\
Family spend. per capita & 0.14 & $0.43^{*}$ & $0.79^{*}$ & $0.51^{*}$ & -0.07 \\
Tax revenues per capita & $0.38^{*}$ & $0.51^{*}$ & $0.47^{*}$ & 0.11 & -0.02 \\
GDP per capita & $0.30^{*}$ & $0.33^{*}$ & $0.42^{*}$ & $0.17^{*}$ & -0.03 \\
Public spend./GDP & $-0.12^{*}$ & $-0.07^{*}$ & -0.03 & 0.05 & 0.03 \\
Family spend./GDP & 0.00 & 0.00 & $0.01^{*}$ & $0.01^{*}$ & -0.00 \\
Tax revenues/GDP & 0.03 & $0.08^{*}$ & 0.02 & -0.03 & 0.00 \\
\hline \hline
\end{tabular}

(d) Model 8 with public spend. and tax revenues, including old-age spend.

\begin{tabular}{lccccc} 
& Year 0 & Year 1 & Year 2 & Year 5 & Year 10 \\
\hline Public spend. per capita & 0.04 & $0.17^{*}$ & $0.35^{*}$ & $0.26^{*}$ & -0.04 \\
Old age spend. per capita & 0.06 & -0.07 & -0.25 & $-0.41^{*}$ & -0.12 \\
Tax revenues per capita & $0.39^{*}$ & $0.50^{*}$ & $0.47^{*}$ & 0.10 & -0.02 \\
GDP per capita & $0.30^{*}$ & $0.35^{*}$ & $0.43^{*}$ & $0.22^{*}$ & 0.03 \\
Public spend./GDP & $-0.12^{*}$ & $-0.09^{*}$ & -0.04 & 0.02 & -0.03 \\
Old age spend/GDP & $-0.02^{*}$ & $-0.03^{*}$ & $-0.05^{*}$ & $-0.04^{*}$ & -0.01 \\
Tax revenues/GDP & 0.04 & $0.07^{*}$ & 0.02 & $-0.05^{*}$ & -0.02 \\
\hline \hline
\end{tabular}

Notes: Year 0 stands for the year of the shock. ${ }^{*}$ denotes statistical significance at the $10 \%$ level. The size of the migration shock is set to 1 incoming individual per thousand inhabitants. For per capita variables, the responses are expressed in percentage change; for variables as a share of GDP, the responses are in percentage points change. 
Table B-9: Responses to migration shock, labor market

\begin{tabular}{|c|c|c|c|c|c|}
\hline \multicolumn{6}{|c|}{ (a) Model 9, baseline model with unemployment rate } \\
\hline & Year 0 & Year 1 & Year 2 & Year 5 & Year 10 \\
\hline Gov. purchases per capita & $0.21^{*}$ & $0.42^{*}$ & $0.47^{*}$ & $0.25^{*}$ & 0.02 \\
\hline Net Taxes per capita & $0.74^{*}$ & $0.95^{*}$ & $0.81^{*}$ & 0.16 & -0.11 \\
\hline GDP per capita & $0.23^{*}$ & $0.29^{*}$ & $0.29^{*}$ & 0.05 & -0.06 \\
\hline Unemp. rate & $-0.10^{*}$ & $-0.14^{*}$ & $-0.13^{*}$ & -0.03 & 0.02 \\
\hline Fiscal balance & $0.10^{*}$ & $0.10^{*}$ & $0.06^{*}$ & -0.03 & $-0.03^{*}$ \\
\hline
\end{tabular}

(b) Model 10 with public spending, tax revenues and unemployment rate

\begin{tabular}{lccccc} 
& Year 0 & Year 1 & Year 2 & Year 5 & Year 10 \\
\hline Public spend. per capita & 0.04 & $0.20^{*}$ & $0.25^{*}$ & $0.16^{*}$ & 0.01 \\
Tax revenues per capita & $0.28^{*}$ & $0.41^{*}$ & $0.31^{*}$ & 0.01 & -0.04 \\
GDP per capita & $0.22^{*}$ & $0.27^{*}$ & $0.24^{*}$ & 0.01 & -0.07 \\
Unemployment rate & $-0.10^{*}$ & $-0.13^{*}$ & $-0.12^{*}$ & -0.01 & 0.02 \\
Public spend./GDP & $-0.08^{*}$ & -0.03 & 0.00 & $0.07^{*}$ & $0.04^{*}$ \\
Tax revenues/GDP & 0.03 & $0.06^{*}$ & 0.03 & 0.00 & 0.01 \\
\hline \hline
\end{tabular}

(c) Model 11 with public spend., tax revenues and unemployment rate, including active labor program spend.

Public spend. per capita

Year 0 Year 1 Year 2

Active labor prog. spend. per capita

$\begin{array}{lllll}0.02 & 0.15^{*} & 0.31^{*} & 0.23^{*} & -0.03\end{array}$

Tax revenues per capita

$1.49^{*}$

$1.20^{*}$

0.57

$-0.16$

$-0.02$

GDP per capita

$0.35^{*}$

$0.44^{*}$

$0.41^{*}$

0.12

$-0.02$

Unemployment rate

$0.27^{*}$

$0.28^{*}$

$0.40^{*}$

$0.20^{*}$

$-0.02$

Public spend. /GDP

$-0.11^{*}-0.15^{*}$

$-0.15^{*}$

$-0.03$

0.01

Active labor prog. spend./GDP

$-0.12^{*}$

$-0.06$

$-0.04$

0.01

$-0.01$

Tax revenues/GDP

$0.02^{*}$

0.00

$-0.01$

0.00

0.04

$0.08^{*}$

$-0.04$

$-0.03$

0.00

(d) Model 12 with public spend., tax revenues and unemployment rate, including unemployment spend.

\begin{tabular}{lccccc} 
& Year 0 & Year 1 & Year 2 & Year 5 & Year 10 \\
\hline Public spend. per capita & 0.02 & $0.14^{*}$ & $0.29^{*}$ & $0.21^{*}$ & -0.03 \\
Unemployment spend. per capita & $-1.71^{*}$ & $-2.44^{*}$ & $-2.03^{*}$ & 0.41 & 0.25 \\
Tax revenues per capita & $0.37^{*}$ & $0.46^{*}$ & $0.41^{*}$ & 0.12 & -0.03 \\
GDP per capita & $0.28^{*}$ & $0.28^{*}$ & $0.40^{*}$ & $0.20^{*}$ & -0.01 \\
Unemployment rate & $-0.11^{*}$ & $-0.16^{*}$ & $-0.15^{*}$ & -0.02 & 0.01 \\
Public spend. /GDP & $-0.12^{*}$ & $-0.07^{*}$ & -0.05 & 0.01 & -0.01 \\
Unemployment spend./GDP & $-0.03^{*}$ & $-0.04^{*}$ & $-0.03^{*}$ & 0.00 & 0.00 \\
Tax revenues/GDP & 0.04 & $0.08^{*}$ & 0.00 & -0.03 & -0.01 \\
\hline
\end{tabular}

Notes: Year 0 stands for the year of the shock. ${ }^{*}$ denotes statistical significance at the $10 \%$ level. The size of the migration shock is set to 1 incoming individual per 1,000 inhabitants. For per capita variables, the responses are expressed in percentage change; for variables as a share of GDP, the responses are in percentage points change. 


\section{B-4 Alternative Definitions of the Population}

Figure B-3: Responses to migration shock with alternative definitions of the Population (a) Population 1st of January
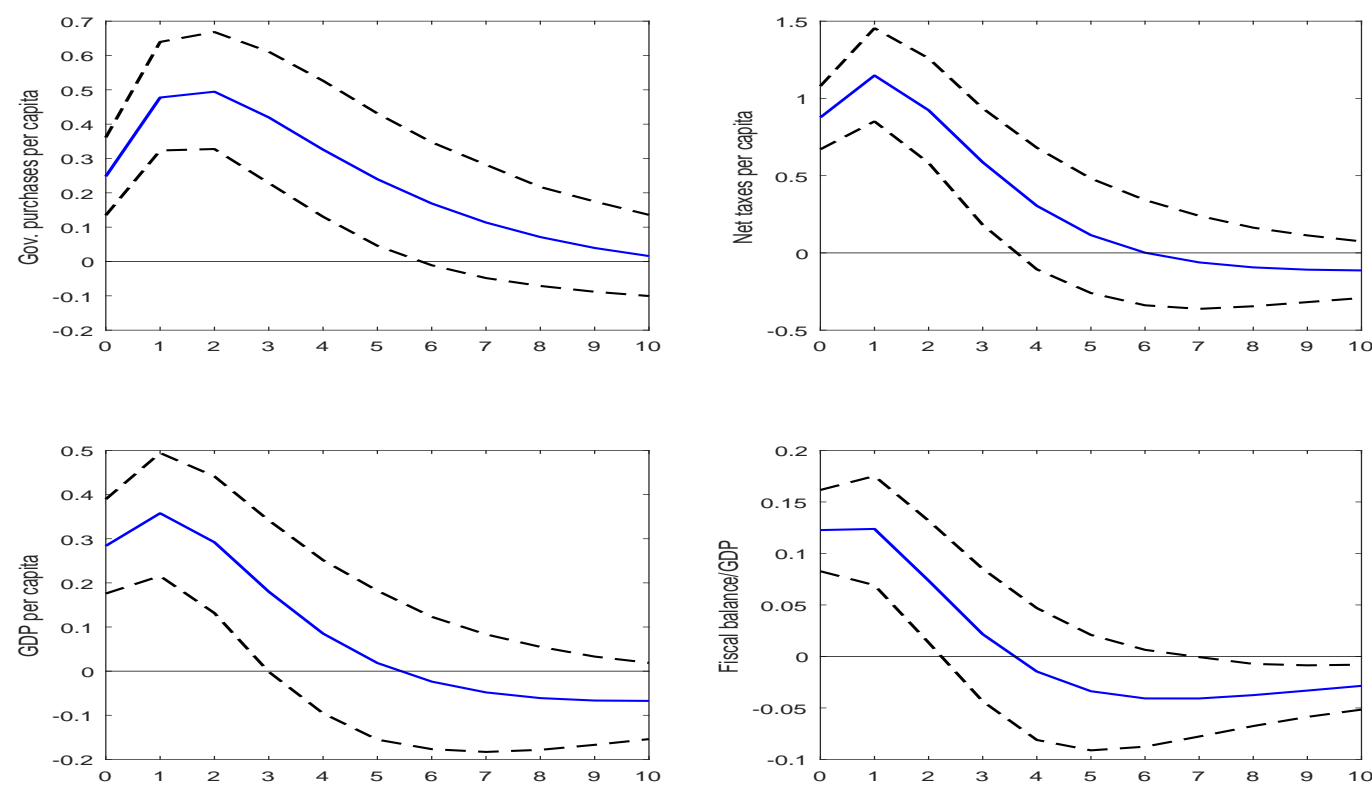

(b) Population 31st of December
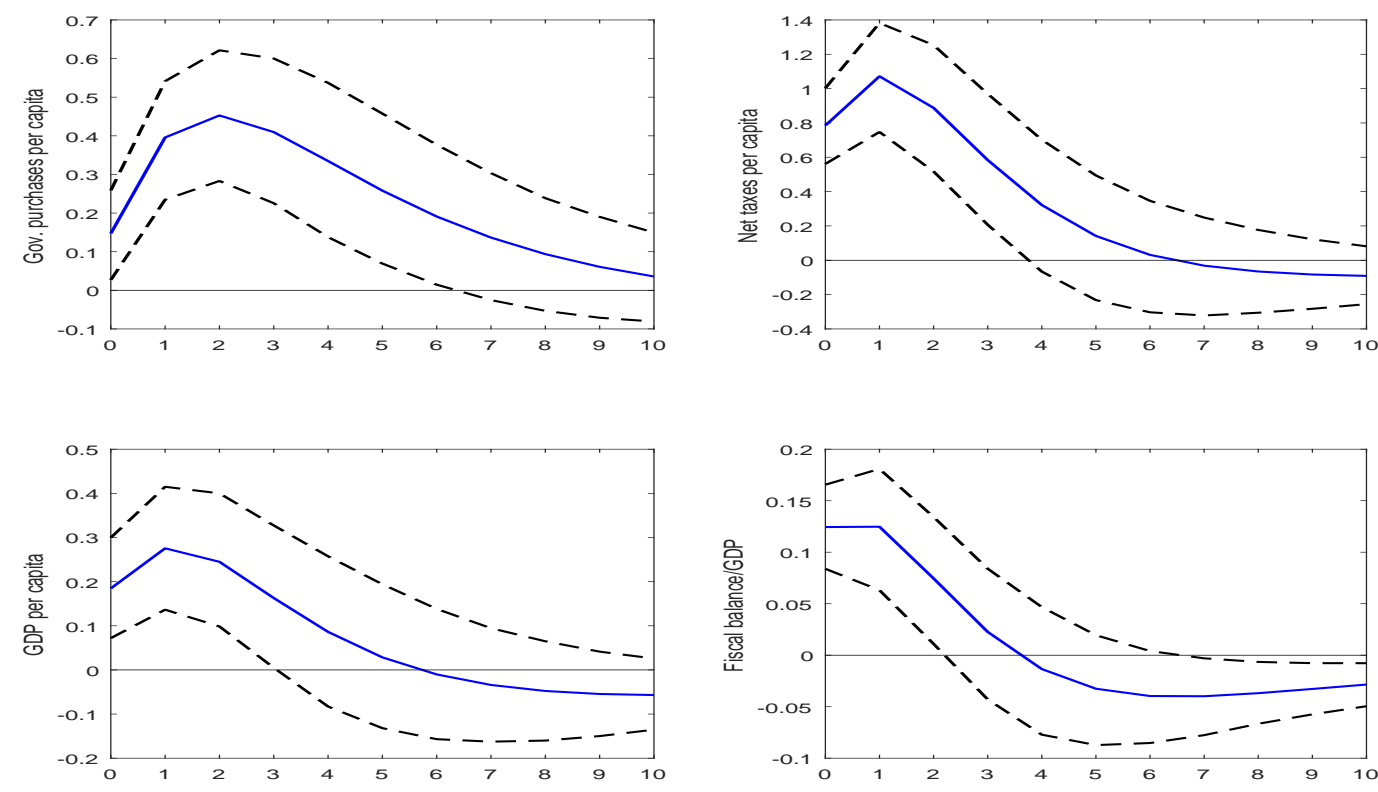

Notes: The solid line gives the estimated impulse responses. Dashed lines give the $90 \%$ confidence intervals generated by Monte Carlo with 5000 repetitions. The size of the migration shock is set to 1 incoming individual per thousand inhabitants. For per capita variables, the responses are expressed in percentage change; for fiscal balance to GDP ratio, the responses are in percentage points change. 


\section{Appendix C Theoretical Model}

\section{C-1 Proof of Proposition 1.}

A simple derivation of equation (11) gives:

$$
\frac{\partial\left(\frac{2 F\left(k_{t},\left(1+\lambda_{t}\right)\right)}{\left[1+\left(1+\beta_{t}\right)\left(1+\lambda_{t}\right)\right]+\frac{1}{\beta_{t-1}}}\right)}{\partial\left(1+\lambda_{t}\right)} \geq 0 \Leftrightarrow \frac{F_{L}^{\prime}\left(k_{t},\left(1+\lambda_{t}\right)\right)}{F\left(k_{t},\left(1+\lambda_{t}\right)\right)} \geq \frac{\left(1+\beta_{t}\right)}{\left[1+\left(1+\beta_{t}\right)\left(1+\lambda_{t}\right)\right]+\frac{1}{\beta_{t-1}}} .
$$

Using the homogeneity property of the production function, the second inequality can be rewritten as:

$$
\frac{F_{L}^{\prime}\left(K_{t}, L_{t}\right) L_{t}}{F_{K}^{\prime}\left(K_{t}, L_{t}\right) K_{t}+F_{L}^{\prime}\left(K_{t}, L_{t}\right) L_{t}} \geq \frac{\left(1+\lambda_{t}\right)\left(1+\beta_{t}\right)}{\left[1+\left(1+\beta_{t}\right)\left(1+\lambda_{t}\right)\right]+\frac{1}{\beta_{t-1}}}
$$

or equivalently as:

$$
\frac{F_{L}^{\prime}\left(K_{t}, L_{t}\right) L_{t}}{F_{K}^{\prime}\left(K_{t}, L_{t}\right) K_{t}} \geq \frac{\left(1+\lambda_{t}\right)\left(1+\beta_{t}\right)}{1+\frac{1}{\beta_{t-1}}}
$$

which using (10) gives (12).

\section{C-2 Proof of Proposition 2.}

Let us define:

$$
g\left(\lambda_{t}\right):=\frac{\theta(1-\alpha)}{\beta_{t}(1+\theta)+\frac{\pi(1-\alpha)}{\alpha\left(1+\lambda_{t+1}\right)}}\left(\frac{1-\kappa \beta_{t}}{\left(1+\lambda_{t}\right)^{\alpha}}-\frac{\pi}{\left(1+\lambda_{t}\right)^{1+\alpha} \beta_{t-1}}\right) .
$$

To establish the first part of the Proposition, we notice that the sign of $g^{\prime}\left(\lambda_{t}\right)$ is the same of the one of $\tilde{g}^{\prime}\left(\lambda_{t}\right)$ where:

$$
\tilde{g}^{\prime}\left(\lambda_{t}\right)=-\alpha \frac{1-\kappa \beta_{t}}{\left(1+\lambda_{t}\right)^{1+\alpha}}+(1+\alpha) \frac{\pi}{\left(1+\lambda_{t}\right)^{2+\alpha} \beta_{t-1}},
$$

from which we deduce:

$$
\left.\tilde{g}^{\prime}\left(\lambda_{t}\right)\right|_{\pi=0}=-\alpha \frac{1-\kappa \beta_{t}}{\left(1+\lambda_{t}\right)^{1+\alpha}}<0, \text { and }\left.\tilde{g}^{\prime}\left(\lambda_{t}\right)\right|_{\pi=\pi_{t}^{\mathrm{sup}}}=\frac{1-\kappa \beta_{t}}{\left(1+\lambda_{t}\right)^{1+\alpha}}>0 \text {. }
$$


Moreover, one has:

$$
\frac{\partial \tilde{g}^{\prime}\left(\lambda_{t}\right)}{\partial \pi}=\frac{(1+\alpha)}{\left(1+\lambda_{t}\right)^{2+\alpha} \beta_{t-1}}>0
$$

To establish the second part of the Proposition, we notice that $\frac{\partial \tilde{g}^{\prime}\left(\lambda_{t}\right)}{\partial \pi}>0$.

\section{C-3 Proof of Proposition 3.}

For a constant $\beta$, the income per capita in $t$ is given by:

$$
y_{t}=\frac{\beta}{1+\beta} \frac{2 k_{t}^{\alpha}\left(1+\lambda_{t}\right)^{1-\alpha}}{\left(1+\lambda_{t}\right) \beta+1},
$$

and its steady state value is thus:

$$
y=\frac{\beta}{1+\beta} \frac{2 k_{0}^{\alpha}(1+\lambda)^{1-\alpha}}{(1+\lambda) \beta+1}
$$

where $k_{0}$ is computed using (21) such that:

$$
k_{0}=\left(\frac{\theta\left(1-\frac{\pi}{(1+\lambda) \beta}-\kappa \beta\right)(1-\alpha)}{\left(\beta(1+\theta)+\frac{\pi(1-\alpha)}{\alpha(1+\lambda)}\right)(1+\lambda)^{\alpha}}\right)^{\frac{1}{1-\alpha}}
$$

At the date of the shock, i.e. in $t=0$, income per capita is given by:

$$
y_{0}=\frac{\beta}{1+\beta} \frac{2 k_{0}^{\alpha}\left(1+\lambda_{0}\right)^{1-\alpha}}{\left(1+\lambda_{0}\right) \beta+1} .
$$

Using Proposition 1, we have:

$$
y_{0} \geq y \Longleftrightarrow \frac{(1-\alpha)}{\alpha} \geq \beta\left(1+\lambda_{0}\right) .
$$

Then, in $t=1$, income per capita is given by:

$$
y_{1}=\frac{\beta}{1+\beta} \frac{2 k_{1}^{\alpha}(1+\lambda)^{1-\alpha}}{(1+\lambda) \beta+1} .
$$


Since we supposed that $\pi>\bar{\pi}$, we have $k_{1}>k_{0}$ and thus $y_{1}>y$. Then, the convergence of $k_{t}$ implies that $y_{t}$ converges to $y$.

Net taxes at time $t$, denoted $\bar{\tau}_{t}$, are given by:

$$
\bar{\tau}_{t}=\frac{\beta}{(1+\beta)} \frac{2 \kappa(1-\alpha) k_{t}^{\alpha}\left(1+\lambda_{t}\right)^{1-\alpha}}{\frac{1}{\beta}+\left(1+\lambda_{t}\right)},
$$

whose value at steady-state, at the time of the shock $t=0$, and at times $t=1,2,3 \ldots$ are respectively:

$$
\begin{aligned}
\bar{\tau} & =\frac{\beta}{(1+\beta)} \frac{2 \kappa(1-\alpha) k_{0}^{\alpha}(1+\lambda)^{1-\alpha}}{\frac{1}{\beta}+(1+\lambda)}, \\
\bar{\tau}_{0} & =\frac{\beta}{(1+\beta)} \frac{2 \kappa(1-\alpha) k_{0}^{\alpha}\left(1+\lambda_{0}\right)^{1-\alpha}}{\frac{1}{\beta}+\left(1+\lambda_{0}\right)}, \\
\bar{\tau}_{t} & =\frac{\beta}{(1+\beta)} \frac{2 \kappa(1-\alpha) k_{t}^{\alpha}(1+\lambda)^{1-\alpha}}{\frac{1}{\beta}+(1+\lambda)} .
\end{aligned}
$$

As for income per capita, we have $\bar{\tau}_{0} \geq \bar{\tau} \Longleftrightarrow \frac{(1-\alpha)}{\alpha} \geq \beta\left(1+\lambda_{0}\right)$, and $\bar{\tau}_{t}>\bar{\tau}$ for all $t=1,2, \ldots$ 